\title{
Resonant Cavity Antennas for 5G Communication Systems: A Review
}

\author{
Azita Goudarzi * (D), Mohammad Mahdi Honari (D) and Rashid Mirzavand (D) \\ IWT lab, University of Alberta, Edmonton, AB T6G 2R3, Canada; honarika@ualberta.ca (M.M.H.); \\ mirzavan@ualberta.ca (R.M.) \\ * Correspondence: agoudarz@ualberta.ca
}

Received: 4 June 2020; Accepted: 30 June 2020; Published: 1 July 2020

check for updates

\begin{abstract}
Resonant cavity antennas (RCAs) are suitable candidates to achieve high-directivity with a low-cost and easy fabrication process. The stable functionality of the RCAs over different frequency bands, as well as, their pattern reconfigurability make them an attractive antenna structure for the next generation wireless communication systems, i.e., fifth generation (5G). The variety of designs and analytical techniques regarding the main radiator and partially reflective surface (PRS) configurations allow dramatic progress and advances in the area of RCAs. Adding different functionalities in a single structure by using additional layers is another appealing feature of the RCA structures, which has opened the various fields of studies toward 5G applications. This paper reviews the recent advances on the RCAs along with the analytical methods, and various capabilities that make them suitable to be used in 5G communication systems. To discuss different capabilities of RCA structures, some applicable fields of studies are followed in different sections of this paper. To indicate different techniques in achieving various capabilities, some recent state-of-the-art designs are demonstrated and investigated. Since wideband high-gain antennas with different functionalities are highly required for the next generation of wireless communication, the main focus of this paper is to discuss primarily the antenna gain and bandwidth. Finally, a brief conclusion is drawn to have a quick overview of the content of this paper.
\end{abstract}

Keywords: fabry-pérot cavity antenna; fifth generation (5G); millimeter wave spectrum; partially reflective surface; resonant cavity antenna

\section{Introduction}

Demand of high traffic capacity and speed in wireless communication systems led to the fifth-generation (5G) technologies [1]. The upcoming 5G technologies provide a multitude of advantages including high data rate, high reliability, and low power consumption. More important, it brings new born technologies to have smart cities and factories based on the industry 4.0 [2]. The millimeter-wave (MMW) frequency band has attracted significant attention among academic and industrial sectors, since it has enormous unlicensed bandwidth in comparison with other frequency bands [3]. Thus, MMW band can take an integral role in 5G communication systems. The MMW spectrum brings about compact structures and higher data rate. However, many concerns are remained, which should be addressed in the future communication technologies. One of these concerns is the high cost and complexity of fabrication processes within the MMW band. Another concern is the high energy loss of the MMW spectrum in comparison with the other frequency bands, which can be addressed by increasing the antenna gain.

New research directions have been done to find the effective solutions to address the aforementioned concerns over the MMW frequency band. Different antenna types with a variety of configurations have been proposed to compensate the high loss and propagation issues such as 
interference of the MMW spectrum. Directional antennas with medium to high gain characteristic are excellent candidates to compensate the high loss of the MMW spectrum compared to the conventional planar antennas. Antenna structures such as reflectors [4] or waveguide horns [5,6] and even array antennas [7] and dielectric lenses [8] are conventional structures, which have potential to achieve high-gain and wideband characteristic. However, they have some issues such as being bulky, heavy and complicated, and having lossy feeding networks, which in turn draws attention to other possible alternative solutions. In fact, designing a proper antenna that meets the requirements of the upcoming $5 \mathrm{G}$ communication systems in a simple, efficient, low-profile structure is of prime importance, which has been the subject of many researches.

There are different types of antennas, such as corrugated antennas [9-11], cavity-backed antennas [12,13], and SIW aperture antennas [14,15] that meet the requirement of having a high gain for $5 \mathrm{G}$ applications. Recently, much attention has been focused on the design of multi-functional antennas, which have a combination of characteristics in one single structure for different applications. In fact, having a high-gain antenna with features such as beam steering and circular polarization while being multi frequency band, compact, and wideband is desired. Such structures are highly required for the next communication systems, since they lead to lower cost, compact size and even lower power consumption. It is still challenging to obtain multiple functionalities in just one antenna structure.

Recently, resonant cavity antennas have been attracting a growing attention due to their planar configuration, low fabrication difficulty, high-gain characteristic and their capability of integration with other systems. Therefore, the RCAs with the capabilities of reconfigurability, polarization conversion, being wideband or multi-band, while keeping high gain features have been investigated in a variety of studies. This type of antennas, which are a promising candidate to be used in the future 5G communication systems over the MMW frequency band, will be reviewed in this paper. redAn example of their potential is the capability to be used in $5 \mathrm{G}$ wireless multiple-input-multiple-output (MIMO) systems due to having a low loss and compact structure with a high-gain characteristic. Besides, RCA structures can achieve steerable radiation patterns with a great radiation performance, which is an essential key for the future 5G base stations and mobile devices. Additionally, the RCAs can offer tilted radiation beam towards a desired direction, which is the demand of mobile communication base stations. Another potential use of the RCAs is in the wireless sensor network (WSN) for future 5G systems due to the requirement of using an efficient antenna with multi-function features to enrich the communication between the nodes [16-20].

\subsection{History}

RCAs were first introduced in 1956 by Trentini [21], who demonstrated how placing a partially reflective surface (PRS) above a waveguide aperture antenna structure can increase the antenna direactivity, significantly. Since then, further studies have been carried out in this area leading to introducing several PRS configurations with different functionalities in combination with various radiating elements inside the structure. In Reference [22,23], Alexopoulos et showed that using full dielectric PRS layers above the antennas can provide a remarkable directivity improvement. Then, in Reference [24,25], Jackson and Oliner conducted more studies on RCAs with multi-layer dielectric PRS. In Reference [26], James et al. added extra discussion to Terentini study and used a three-layer PRS to increase the gain of an aperture antenna. The conventional RC structures have utilized thick full dielectric or multi-layer PRS structures. By emerging electromagnetic band gap (EBG), metamaterial (MTM), and frequency selective surface (FSS) structures, the trend of studies changed to the design of metallo-dielectric PRS layers to take advantage of fewer layers, thinner layers, more degrees of freedom, and layers with flexible properties.

In the literature, RCAs have associated with different terminologies such as electromagnetic band gap (EBG) [27,28], RC structures [29], 2-D leaky-wave (LW) structures [30,31], PRS [32], and Fabry-Pérot Cavity (FPC) structures [33]. RCA structures consist of a PRS in parallel with a perfect electric/magnetic conductor or an impedance surface, which establish a cavity, fed by a main radiating 
element inside the cavity to excite the entire structure [21]. Open-ended waveguide, patch antenna, stacked antenna, dielectric resonant antenna (DRA), dipole antenna, and crossed bowtie dipole can be used as the main radiating element inside the cavity. The PRS layer might have different configurations as will be discussed later. It can be a full dielectric structure or a periodic structure composed of an array of metallic unit cells. Due to having a cavity with reflective surfaces, multiple reflections of electromagnetic wave happen. A proper cavity thickness (the distance between the PRS and the ground plane) can superimpose in-phase transmitted waves, which enhances the antenna gain significantly. The phase and magnitude of the PRS reflection behaviour have remarkable impact on the performance of the RCAs in terms of gain, bandwidth, beam angle and aperture efficiency. Therefore, designing the PRS structures has an imperative role in the design of the RCAs to achieve the desired performance.

\subsection{Analytical Methods}

The design of RCA structures for desired radiation performances, requires an appropriate theoretical analysis. Many studies have been focused on how these structures can be analyzed, which led to a variety of analytical methods such as ray tracing, transmission line (TL), LW, EBG, and the principle of reciprocity methods. Among the mentioned analytical methods, the ray tracing, $\mathrm{TL}$, and LW methods are more used in the literature. In this subsection, a brief review of these three methods is prepared, and a short comparison between them is drown.

RCAs are parallel-plate waveguides leading to the leakage of the ray and known as 2-D periodic leaky-wave antennas (LWAs) [34]. Leaky-wave antennas are considered as antennas with a directive beam, scanning the space as a function of frequency. Leaky-wave antennas are a kind of phased array antennas without phase shifters, which leads to a compact structure with a low energy consumption. There are many studies in the literature in which the functionality of the resonant cavity is discussed by LW method [25,30,31,35-38]. Since comparing to other methods, this method is more efficient and accurate for different configurations of the RCAs; recent advanced studies are carried out using LW models, especially those with steering beam functionalities [34,39-41]. The transverse equivalent network model might be used to derive proper formulas in terms of the angle of the beam, gain, beamwidth, leaky-wave phase and attenuation constants of the structure. The propagation constant is dependent on the PRS reflection coeficient and the distance between the ground plane and the PRS structure placed above the main radiating element.

Another analysis technique for the RCA structures is the ray tracing method. The ray tracing method was first introduced by Terentini [21], in which the RCA is analyzed as a resonant microwave cavity structure known as a Fabry-Pérot cavity. The resonance condition, which is dependent on the phase and magnitude of the reflection coefficient of the PRS needs to be satisfied in order to improve the radiation characteristics of the antenna. According to the resonance condition, the distance between the PRS and the ground plane layers are adjusted to create in-phase superposition of waves leaking out from the structure, which leads to high directive radiation pattern. In the ray tracing model, the diffracted rays are not considered since the structure size is assumed infinite. Consequently, this model gives initial design values, which facilitates the designing process; however, it is not as accurate and general as leaky-wave analyses, due to having some approximations assumed. In fact, this method is more applicable when the goal is to increase the antenna gain and bandwidth, and even to change the antenna polarization $[29,42]$.

The transmission-line (TL) method, as the ray tracing method, gives the initial values of antenna design, making it straightforward and time efficient. Many studies have been carried out to demonstrate the functionality of the resonant cavity structure by the TL model $[22,23,30,35,38,43,44]$. In [22], the TL analysis is used to derive some formulas related to the bandwidth, gain, and beamwidth of the RCAs. For this purpose, the entire RCA structure is modeled by TLs with different characteristics, and some lumped elements. As a result, the thickness of different parts and the properties of the PRS in terms of refection coefficient are calculated in order to improve radiation performance of the RCA structure. Using this method resulted in better evaluation of the directivity of RCAs [44]. 


\section{Research Directions}

The demand for compact high-gain antennas with simple feeding networks has highly increased for the next generation of communication systems. The RCAs have attracted the interest of antenna designers for a variety of study directions. The latest studies on the resonant cavity structures combined with other newly PRSs and main radiating structures demonstrate the flexibility of RCAs to be designed over MMW spectrum. In this section, the study directions of the RCAs with the recent investigations and applicable examples, specially over the MMW frequency band, are reviewed.

\subsection{3-dB Gain Bandwidth Improvement}

RCAs are regarded as resonant structures with the drawback of narrow 3-dB gain bandwidth [36,37,45,46]. In Reference [45], the inverse proportionality between the maximum gain and $3-\mathrm{dB}$ gain bandwidth of the RCAs is discussed and proved theoretically by the ray tracing analytical method. Higher gain contributes to narrower bandwidth, which has been considered as one of the concerns that has got the attention of researchers for many years. Consequently, many studies with different methods have been introduced to provide a solution to tackle the mentioned shortcomings of the RCAs. This section deals with presenting different methods carried out to increase the bandwidth of the RCAs.

\subsubsection{Positive Reflection Phase Gradient}

Inverting the reflection phase gradient of the PRS unit cell to achieve a positive slope is among the most famous and applicable methods in order to obtain wider 3-dB gain bandwidth in the design of the RCAs. References [47,48] are among the first studies conducted to demonstrate the possibility of achieving a positive reflection phase gradient to increase the 3-dB gain bandwidth. Changing the phase gradient behaviour can be achieved by using multi-layer PRS structures [49-56], thick full-dielectric PRSs [57], and thin one-layer metallo-dielectric PRSs [29,48,58-62]. One reason behind using multi-layer PRS structures is creating multiple resonances at different frequencies, which can satisfy the multi resonance conditions over a desired bandwidth. Permitivity and thicknesses of the dielectric slabs, the distances between layers, and other parameters have impact on creating multiple resonant frequencies. It is worth noting that using multi-layer PRSs make the RCAs thicker which might be one of the concerns in some applications.

Several studies have been focused on achieving wider 3-dB gain bandwidth using PRS structures with positive phase slope over millimeter wave spectrum [40,63-65]. As an example, in Reference [65], a wideband high-gain MMW FPCA with the operating frequency of $60 \mathrm{GHz}$ is introduced. A printed ridge-gap waveguide (PRGW) technology is used as the slot antenna feed, because it is a proper candidate to suppress the surface waves with a good functionality over the MMW spectrum. The PRS is composed of gridded square patch (GSP) and square slot-loaded patch (SSLP) structures etched on two different dielectric layers. The configuration of the PRS unit cell, PRGW, and FPCA structures are demonstrated in Figure 1. The wideband characteristic is achieved by using a double-layer PRS unit cell with positive reflection phase gradient as demonstrated in Figure 2a. The " $a$ " is used as a scale factor to control the phase of the unit cell. A maximum gain of $16.8 \mathrm{dBi}$ and 3-dB gain bandwidth of $12.5 \%$ are achieved as shown in Figure $2 \mathrm{~b}$.

\subsubsection{PRS Unit Cell with Sharp Resonance}

In the studies reviewed in the previous subsection, it was indicated that having a resonant frequency at the middle of a desired frequency band with a positive phase gradient leads to a wider $3-\mathrm{dB}$ gain bandwidth. In some studies, it is proved that having a sharp resonance at the centre of a frequency band results in 3- $\mathrm{dB}$ gain improvement [56,66-68]. The phase variation can get a 180 degree jump at a resonant frequency to achieve a wide 3-dB gain bandwidth. 


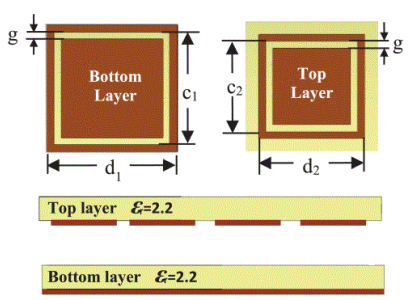

(a)

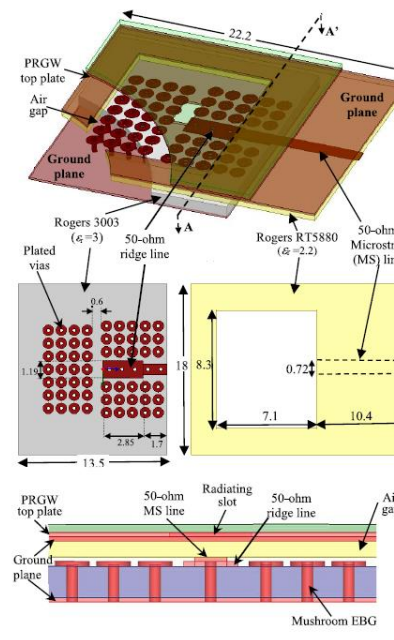

(b)

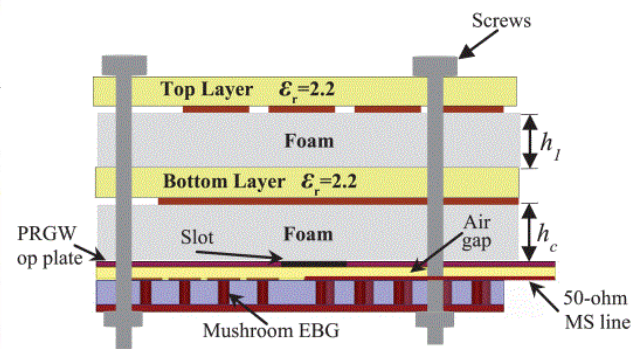

(c)

Figure 1. Configuration of a wideband RCA along with a PRS with positive reflection phase: (a) Unit cell of PRS; (b) Main radiating element (PRGW); (c) Entire structure [65].

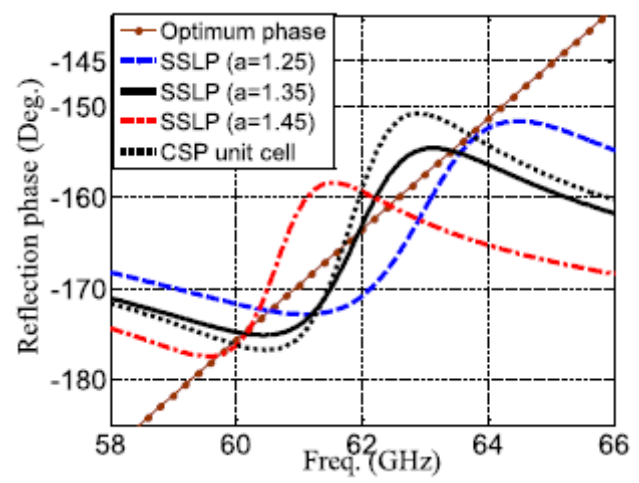

(a)

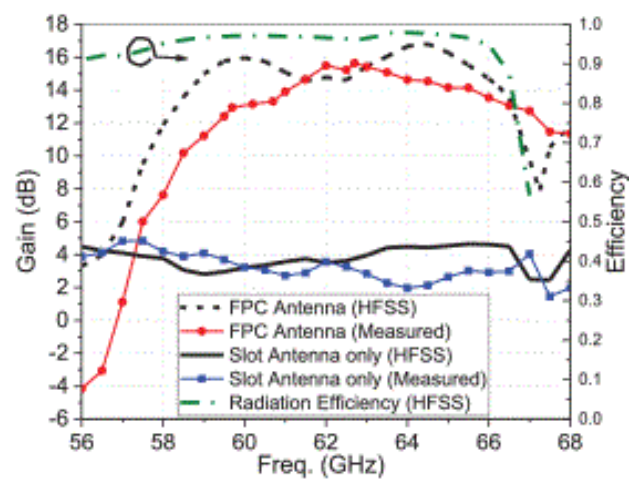

(b)

Figure 2. (a) Reflection phase of the PRS unit cell; (b) Measured and simulated gain and efficiency of the RCA in [65].

In Reference [67], as demonstrated in Figure 3, a dual-layer full-dielectric PRS structure with a high permitivity laminate substrate is proposed to provide a sharp resonant frequency. A crossed dipole is used as the main radiator inside the RCA structure which can result in a wide impedance bandwidth and suitable $\mathrm{CP}$ characteristic. Figure 4a demonstrates the behaviour of reflection coefficient of the proposed PRS with a sharp resonant frequency. As can be seen, the sharp resonance creates extra frequencies (except the center frequency) to satisfy the resonance conditions which is the reason to make the antenna wideband. The incorporation of the PRS and crossed dipole contributes to a 3 - $\mathrm{dB}$ gain bandwidth of $50.9 \%$ with a maximum gain of $15 \mathrm{dBic}$, as can be seen in Figure $4 \mathrm{~b}$. It should be noted that the optimum results are provided by optimizing the distance between the PRS layers along with their size, and the distance between the ground plane and the PRS layers. The proposed antenna possess simple and compact geometry while providing a high gain and circular polarization, which makes it a suitable candidate to be used in base stations. 


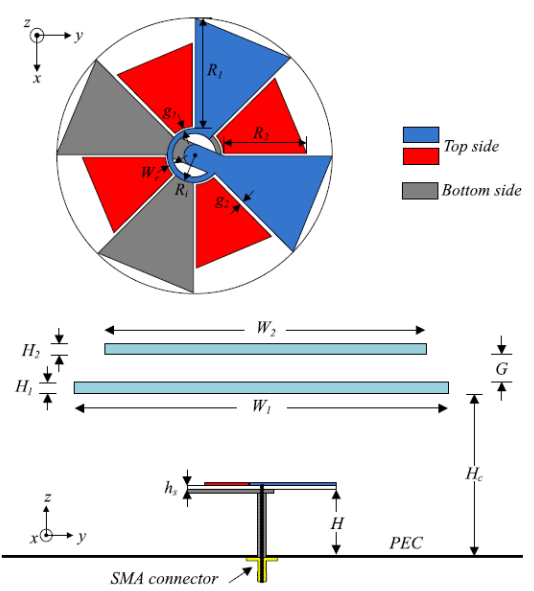

(a)

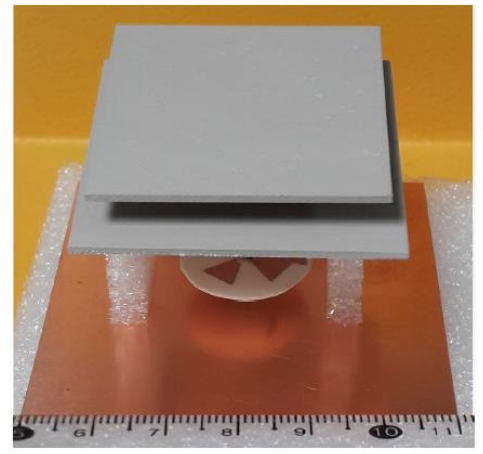

(b)

Figure 3. Configuration of a wideband RCA with a PRS of sharp resonance: (a) Entire geometry; (b) Fabricated structure [67].

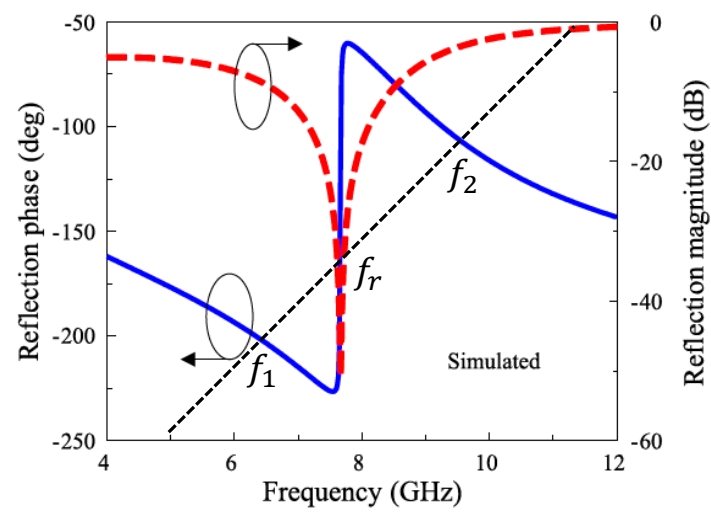

(a)

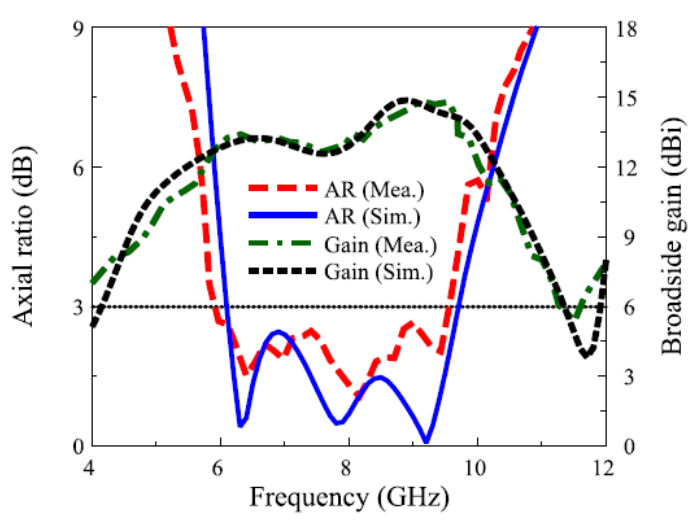

(b)

Figure 4. (a) Reflection phase and magnitude of the PRS unit cell; (b) AR and gain. [67].

\subsubsection{New Configuration of PRS Structures: Nonuniform PRS Structures}

Recent non-uniform configurations of superstrates mostly presented by Baba and Hashmi et al., have been designed to provide a significant increment in 3-dB gain bandwidth of the RCAs [28,69-72]. The proposed PRS structures have taken advantage of the integration of different dielectric substrate slabs with different either thickness or permitivity. Basically, such structures are mainly used to compensate the non-uniform phase distribution of the RCA aperture as will be discussed later in the next section. In Reference [69], a planar PRS layer consisted of dielectric slabs with different permitivities is proposed. The proposed PRS named as transverse permitivity gradient (TPG) is a single-layer planar structure with the capability of the aperture phase correction using different sections with different permittivities. Next, Hashmi et al. demonstrated the possibility of a PRS structure composed of multiple dielectric slabs with different permitivity and thickness in order to improve the 3-dB gain bandwidth of a RCA $[28,70]$. They also investigated the PRS structures with stepped configurations and indicated how these stepped configurations can increase the antenna gain over a wide bandwidth. In Reference [71], the PRS structure is a stepped configuration with laminate substrates of different permitivity and thickness, whereas in [72], the PRS is the similar stepped configuration with just different thicknesses. A slot radiator fed by a waveguide is used as the main radiator for these structures. 
Recent investigations with stepped configurations have been done in millimetre wave frequency band to increase the antenna bandwidth $[32,73,74]$, which shows the flexibility of RCAs for different frequency bands. In Reference [74], the application of two different non-uniform PRS structures to enhance the 3- $\mathrm{dB}$ gain bandwidth and maximum gain of the RCA are investigated over the MMW spectrum. The first PRS is composed of a four concentric full dielectric rings of different permitivity and thickness, whereas the second PRS is made of a single laminate substrate with the same permitivity and different thicknesses. Both of the PRS structures have an stepped configuration, and an open-ended WR-15 waveguide is used as the main radiator inside the cavity to feed the antenna. The antenna structure without PRSs and PRS prototypes are demonstrated in Figure 5. The antenna with the second PRS has a maximum measured gain of $19.5 \mathrm{dBi}$ with a proper matching from $55.2 \mathrm{GHz}$ to $65 \mathrm{GHz}$. The simulated and measured results are displayed in Figure 6. These kinds of non-uniform PRS structures achieve remarkable gain-bandwidth product (GBP), which is a true merit used in the comparison between different antennas. The proposed antenna in [74] has a simple structure with a high gain and low cross-polarization, which makes it beneficial for base stations, point-to-point communication systems, autonomous radars, remote sensing satellites, and Internet of things (IoT).

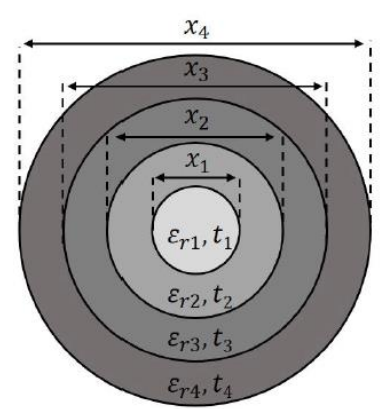

(a)

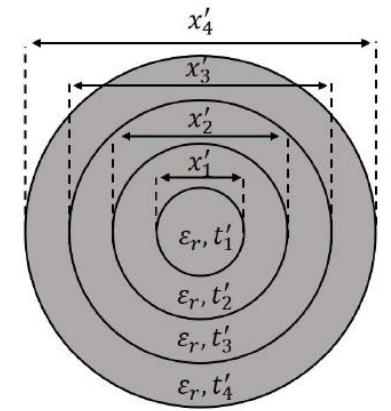

(b)

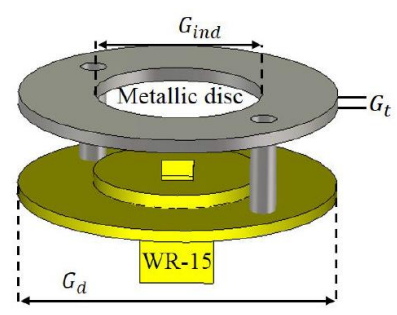

(c)

Figure 5. Configuration of a RCA with stepped PRS: (a) First PRS configuration; (b) Second PRS configuration; (c) Entire structure [74].

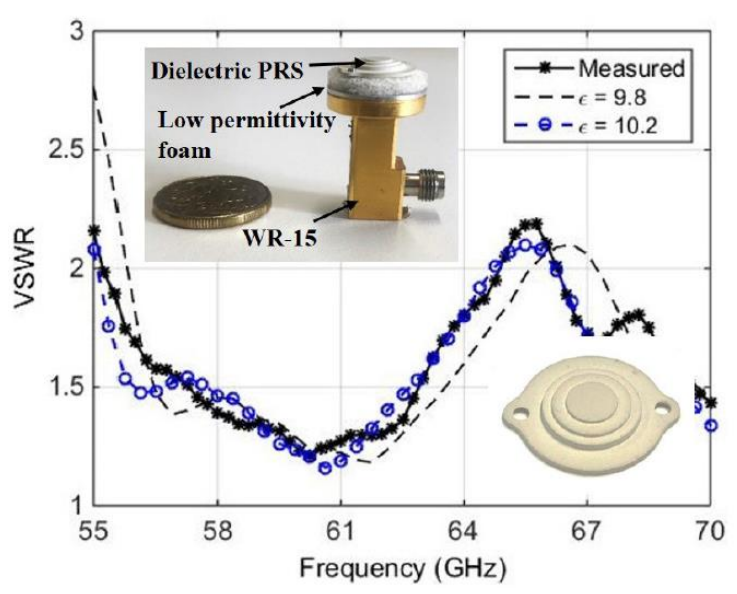

(a)

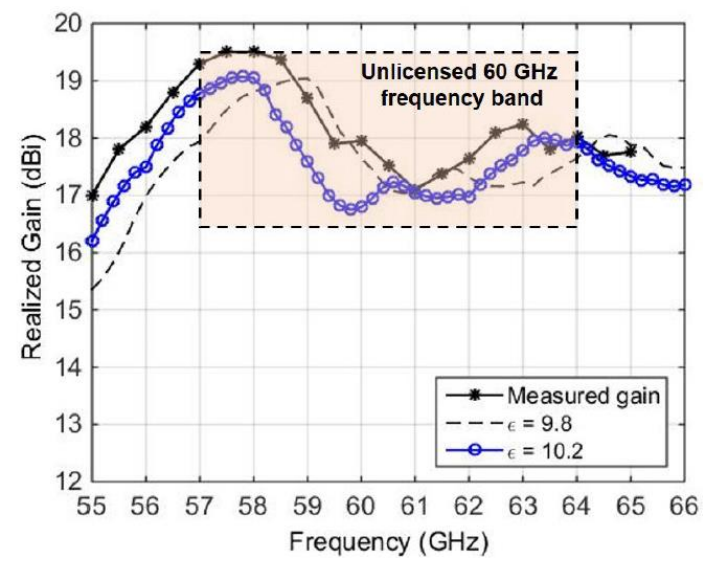

(b)

Figure 6. Simulated and measured results of RCA with stepped PRS: (a) VSWR; (b) Gain [74].

\subsubsection{Shape Manipulation of the Conventional RCA Configuration}

The demand for wideband high-gain antennas have led researchers to seek different and novel methods to efficiently enhance the antenna bandwidth without sacrificing the antenna performance. It is proved that the performance of FPCAs can be improved by curving the ground plane or PRS 
architecture. In Reference [75-77], manipulating the configuration of the ground plane and PRS structures so that the distance between the PRS layer and the ground plane gradually gets unequal values for different parts of the RCA structures are considered by different methods. These manipulated structures are capable to compensate and correct the phase and magnitude distribution far from the center of the PRS structure that results in a broader 3-dB gain bandwidth. In Reference [75], a shaped ground plane with a semi-spherical configuration is used to make the 3- $\mathrm{dB}$ gain bandwidth wider. The configuration of the proposed RCA structure is shown in Figure 7a. The antenna performance is compared with the performance of a conventional RCA with a flat ground plane, and the results are shown in Figure $7 \mathrm{~b}$. The RCA structure reported in [75] provides a measured 3-dB gain bandwidth of $25 \%$ with a maximum gain of $17.7 \mathrm{dBi}$ as demonstrated in Figure 8. Similar works have been done for MMW spectrum by using unconventional RCA structures $[78,79]$.

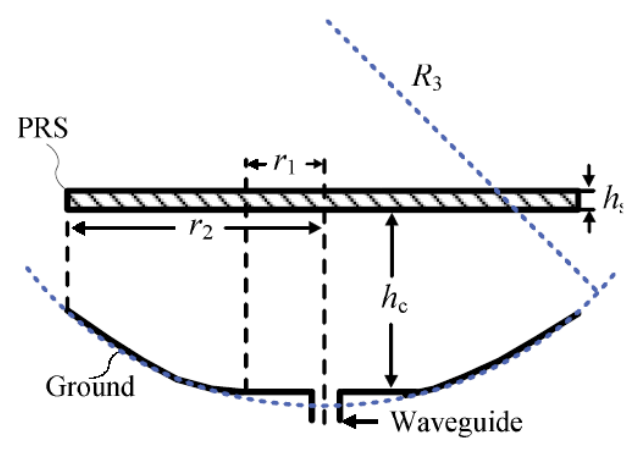

(a)

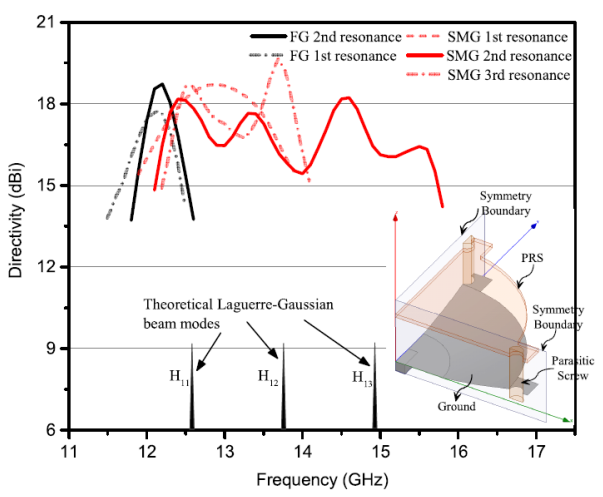

(b)

Figure 7. (a) RCA with a modified ground plane; (b) Directivity [75].

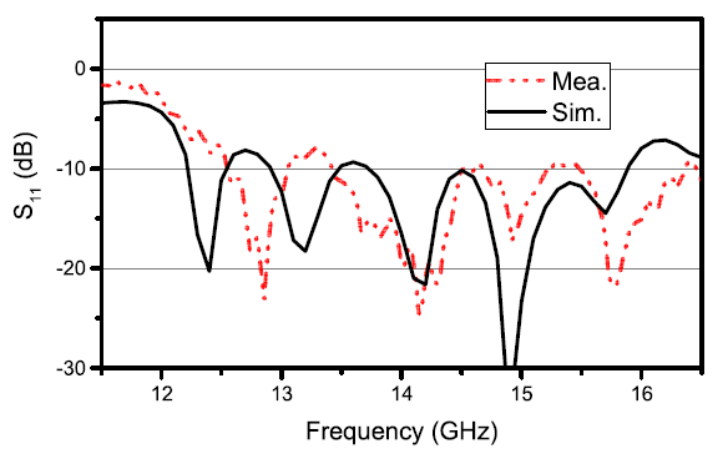

(a)

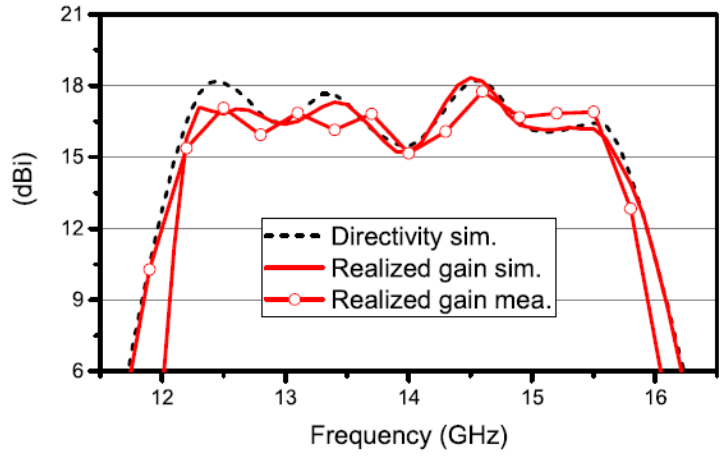

(b)

Figure 8. Performance of the RCA with modified ground plane: (a) Reflection coefficient; (b) Realized gain [75].

\subsubsection{Array Feed}

Using array antennas instead of single main radiator inside the cavity structure is another conventional method to increase the 3-dB gain bandwidth. This idea has been investigated in many studies $[27,33,43,80]$, which mostly used complicated feeding networks. In Reference [43], an array of patch elements are used as the radiators. Besides, by adding two PRS layers above the array antennas, the radiation performance of the antenna is improved. The antenna configuration and the results of the antenna gain are demonstrated in Figure 9. As can be seen, the maximum gain of a $2 \times 2$ array patch antenna without any PRS layer is almost the same as a RCA with a single patch as the main 
radiator. Similarly, the results are same for a $4 \times 4$ patch array without PRS and a RCA with a $2 \times 2$ patch array as the main radiator.

Although using array source inside the cavity results in reasonable improvement of the gain and $3-\mathrm{dB}$ gain bandwidth, it is not a good idea for millimeter wave spectrum. Difficult fabrication process and high loss caused by feed networks are two main issues that reduce the tendency to use array structures at those frequencies.

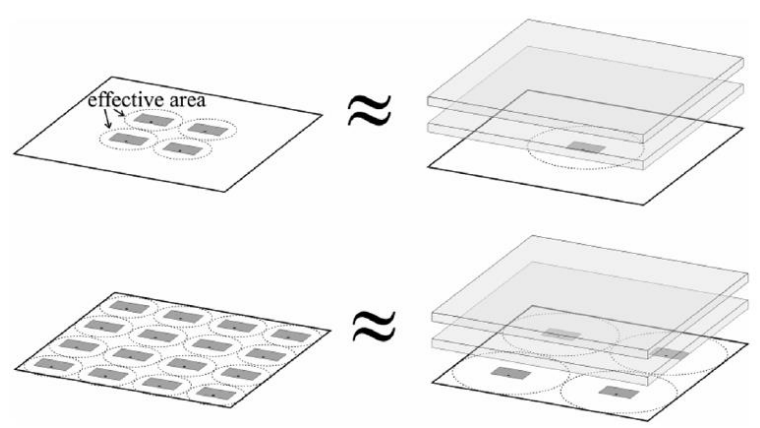

(a)

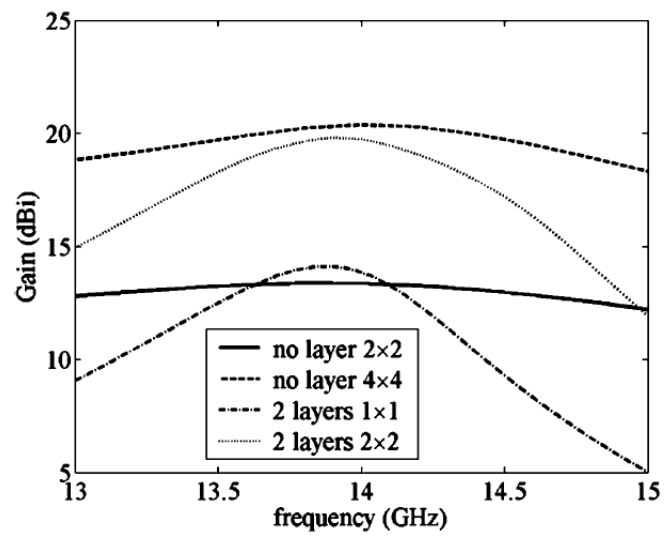

(b)

Figure 9. RCA with an array source radiator: (a) Schematic configuration; (b) Gain of the antenna [43].

\subsection{Directivity Enhancement: Aperture Efficiency Improvement}

There is another group of studies which have been conducted to compensate the non-uniform aperture magnitude and phase distribution of the conventional RCA structure $[66,81-88]$ and as a result to enhance the antenna directivity. Conventional and classical structures of the RCAs have non-uniform aperture phase and magnitude distribution, which result in the reduction of the antenna radiation performance. Compensating the non-uniform field distribution of a RCA aperture is an effective attempt to increase the antenna directivity and decrease side lobe level. Some of the studies have focused on the phase compensation [66,81-85], whereas the others have investigated the aperture magnitude compensation $[86,87]$ for enhancing the antenna performance. In a few studies such as [88], both phase and magnitude are compensated to create remarkable aperture efficiency. Using a non-uniform PRS structure is the most common method to compensate the non-uniform magnitude and phase distribution of electric filed over the antenna aperture. Using phase compensation method is more applicable, because it leads to greater improvement in comparison with the magnitude compensation.

In Reference [82], an stepped superstrate is used to compensate the non-uniform aperture phase distribution of a RCA, which leads to a higher directivity and aperture efficiency. The structure is a phase rectifying transparent superstrate (PRTS), which was fabricated by 3-D printing technology and the main radiating element is a microstrip patch antenna with a full-dielectric PRS structure illustrated in Figure 10. Figure 11 shows the phase distribution and the directivity of the antenna, before and after applying PRTS structure. As can be seen, the phase distribution becomes almost uniform all over the aperture, since the PRTS placed above the PRS compensates the phase delay. According to the Figure 11c, the directivity gets a significant improvement when that the PRTS is placed above the entire RCA structure.

Additionally, a few other methods, such as using different geometries and sizes for the PRS structures located at different distances from the center of the aperture, have been used in the literature to improve the gain and aperture efficiency of the RCAs $[79,89,90]$. 

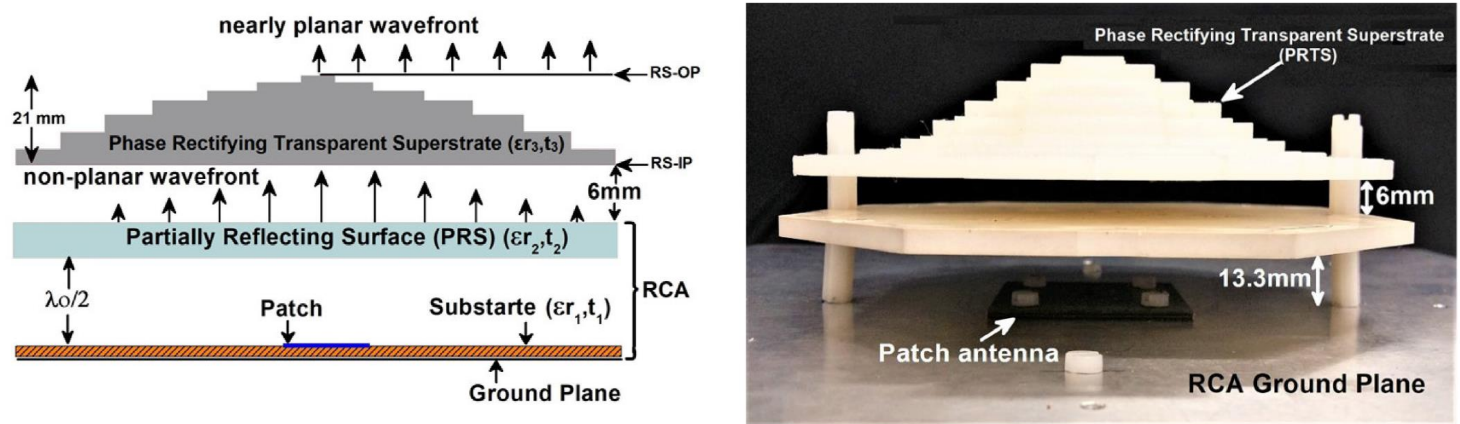

(a)

(b)

Figure 10. Configuration of a RCA with an aperture phase distribution compensation: (a) Schematic; (b) Fabricated prototype [82].

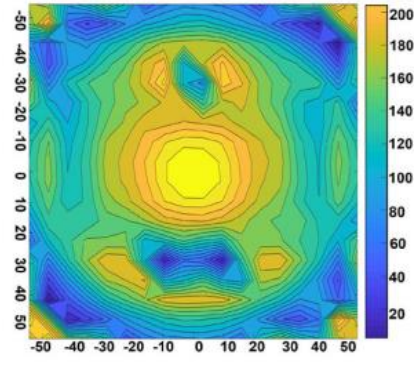

(a)

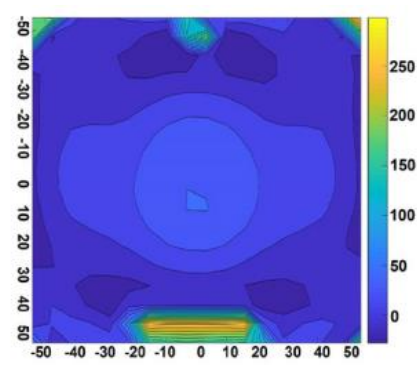

(b)

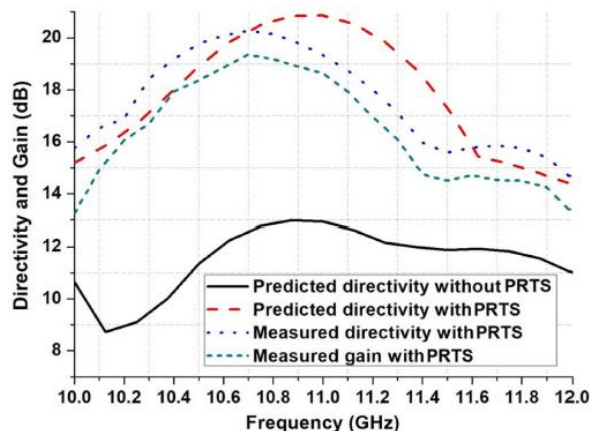

(c)

Figure 11. Results of the RCA with the aperture phase correction: (a) Aperture phase distribution after correction; (b) Aperture phase distribution before correction; (c) Antenna directivity [82].

\subsection{Circular Polarization}

High-gain wideband circularly-polarized (CP) antennas are required in many applications such as radar, satellite, and mobile communication systems. In comparison with LP, CP antennas take advantage of lower the interference in multipath environments. Besides, $\mathrm{CP}$ antennas are independent of polarization between transmitters and receivers. Having RCAs with high-gain, wideband, and circular polarization has been a challenge which has been addressed in many studies [67,68,91-104].

Usually two different methods are used to achieve a high-gain CP RCA. The first one is to use a $\mathrm{CP}$ main radiator element and the radiation improvement of the entire structure is obtained through utilizing a PRS structure whose behaviour is independent of the polarization [67,68,91-97].

The other method is known as self-polarizing RCA. In this method, the linear-to-circular polarization conversion is the subject that is studied. A linearly polarized (LP) antenna is used as the main radiating feed and its polarization is converted to circular through using a proper PRS placed above the RCA [98-104]. This method is preferred, since it does not need any feeding networks to make circular polarization; however it might not obtain a wide bandwidth.

Many studies have been reported for designing a high-gain CP RCA over the MMW spectrum in the literature [42,105-107]. Some of them present a practical application of the CP RCAs for the 5G communication systems. In Reference [42], a CP high-gain RCA is designed for 5G multiple-input multiple output (MIMO) applications over $26 \mathrm{GHz}$ to $31 \mathrm{GHz}$. A single-layer full dielectric PRS structure with a sharp resonant frequency is used to enhance the antenna radiation performance over a wide frequency band. A CP truncated patch antenna with a proper slot is placed inside the cavity to 
illuminate the entire structure as demonstrated in Figure 12. Figure 13 exhibits a 3-dB AR bandwidth of $17.5 \%$ with a maximum gain of $14.1 \mathrm{dBic}$ achieved by the structure.

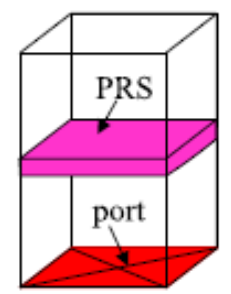

(a)

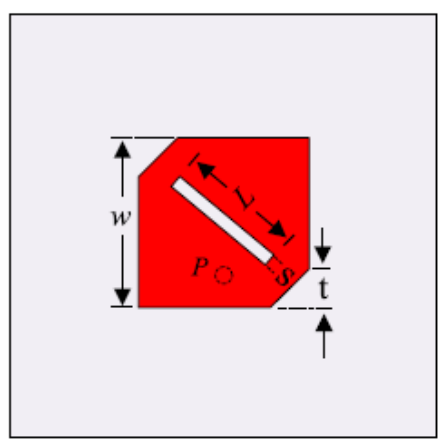

(b)

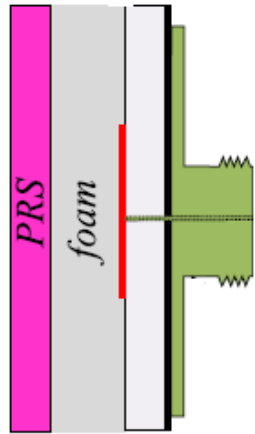

(c)

Figure 12. Configuration of a CP RCA: (a) Unit cell; (b) Main radiator; (c) Entire RCA structure [42].

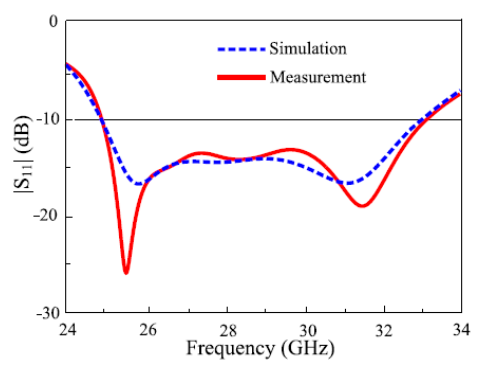

(a)

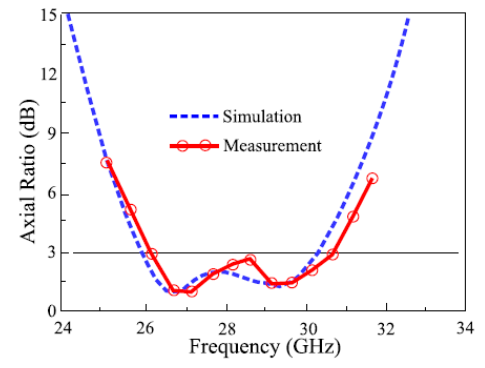

(b)

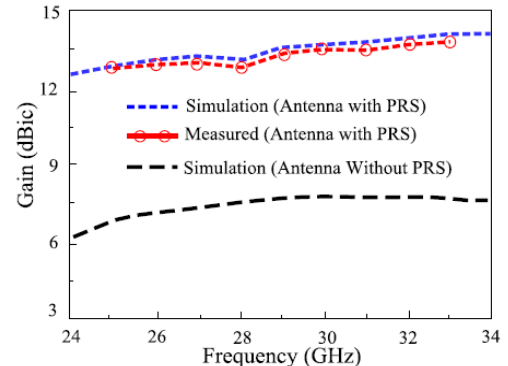

(c)

Figure 13. Measured and simulated results of the CP RCA reported in [42]: (a) Reflection coefficient; (b) AR; (c) Gain.

\subsection{Reconfigurable RCAs}

Reconfigurability of the RCAs is the capability of their structures to alter their radiation features by electrical elements or mechanical mechanism. A reconfigurable antenna might use different methods to alter operation frequency, radiation pattern, polarization, beamwidth, or even a combination of these variables.

Multi functional antennas are proper solution for newborn 5G millimeter wave frequency band, where the large size of the systems and the extra equipment to provide other functions are considered as potential problems. Reconfigurable antennas can offer other functionalities over multiple bands and can be efficient in variable environments in case they face a limitation or a new situation. Consequently, reconfigurable RCAs, due to their simple feed network and high-gain characteristic, can be considered as an efficient and low-cost option to mitigate the significant challenges in 5G applications. There are many studies in the literature concentrated on reconfigurable RCA structures. These studies investigate frequency [108-112], beamwidth [113-115], and polarization [116-127], and pattern reconfigurability [128-139].

Polarization reconfigurability can be achieved by using either a reconfigurable main radiating element [116-122] or a dependent polarization PRS [123-127]. In Reference [140], a four-polarizationreconfigurable aperture-coupled patch antenna is designed as the main radiator of a RCA structure, which works with two different linear polarizations. The PRS structure is designed with adjustable reflection phase consisting of four PIN diodes to steer the RCA beam. The entire RCA configuration 
is shown in Figure 14. By a proper arrangement of the main radiating elements and PRS structure, a dual-polarized 2-D beam-steering functionality is achieved as shown in Figure 15.

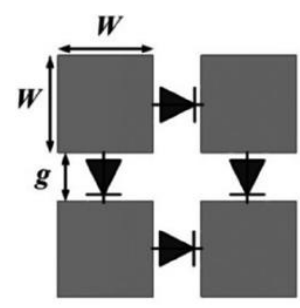

(a)

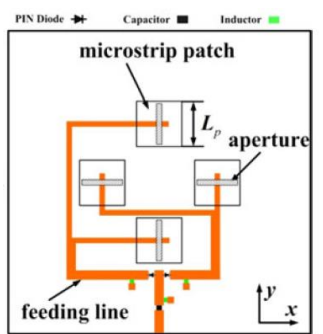

(b)

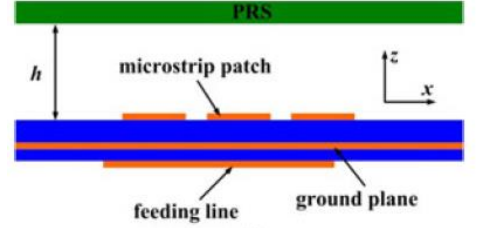

(c)

Figure 14. Configuration of a RCA with dual-reconfigurability feature: (a) Unit cell; (b) Main radiator; (c) Entire RCA structure [140].

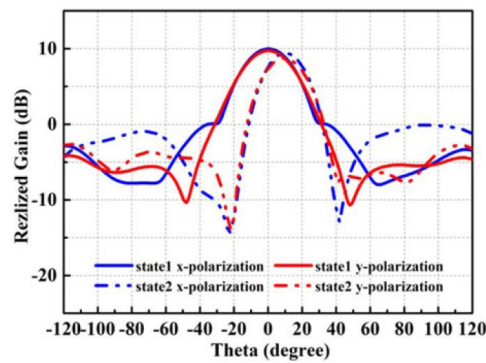

(a)

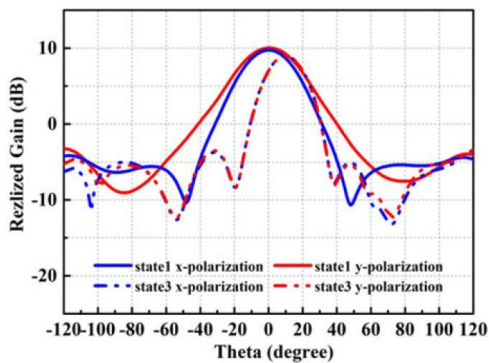

(b)

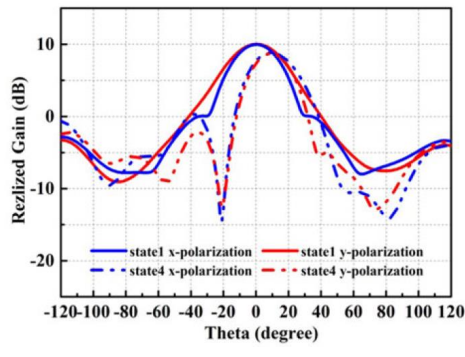

(c)

Figure 15. Radiation patterns of the RCA structure reported in [140] at three different planes: (a) $0^{\circ}$; (b) $45^{\circ}$; (c) $90^{\circ}$.

Beam steering property is one of the demands of the new generation of wireless communications that enables the wide coverage. Using phased array antennas is the conventional solution for the communication coverage, in which the beam steering is realized by carefully adjusting the phase difference between the array elements. However, conventional phased array antennas suffer from high-cost fabrication process and complicated feeding networks with significant loss.

A variety of investigations have been carried out to demonstrate the capability of the RCAs to achieve reconfigured pattern in the millimeter wave frequency band. Many studies proposed that the main radiator placed inside the RCA structure takes the responsibility of the pattern reconfiurability [141-143] and the antenna radiation performance can be improved by using PRS structures. Other studies have proposed suitable PRS structures to manipulate the RCA radiation pattern instead of using a fed antenna with complicated feed networks [128-139]. PRS structures provide more degree of freedom to control the beam of the main radiator with other functionalities simultaneously without applying extra equipment. Therefore, many RCA structures have been proposed with either both pattern and polarization reconfigurability or pattern and beamwidth reconfigurability $[115,140,144-146]$.

In References $[139,146]$, the possibility of using RCA with reconfigurable pattern characteristic for 5G is illustrated. In Reference [139], the beam tilting of a RCA is investigated through four different techniques at $60 \mathrm{GHz}$. The techniques used for tilting the beam include wedge-shaped dielectric lens (WSDL), discrete multilevel grating dielectric (DMGD), printed gradient surface (PGS), and perforated dielectric gradient surface (PDGS), which are based on the phase gradient surface method. Among the mentioned techniques, PGS and PDGS have better performance inorder to provide reconfigurability feature. Figure 16a shows a printed ridge gap waveguide (PRGW) used as the main radiating element 
in [139]. Six different structures of the PGS and PDGS were proposed and their functionality is investigated while they are placed above the main radiator. Three designs \#1,\#2,\#3 for PGS and PDGS structures were done for different tilt angles. A maximum gain of around $22 \mathrm{dBi}$ is achieved when these structures are used to tilt the beam of the RCA. The simulated and measured results achieved by using these six superstrates are illustrated in Figure 17. As shown, the tilted beam angles of $\theta=14^{0}$, $\theta=27^{0}$ and $\theta=44^{0}$ are achieved by placing every design of PGS or PDGS above the main radiator. The proposed antenna in [139] is a potential candidate for narrow-band communication systems. It can be used in mobile devices due to its compact configuration with reconfigurable radiation pattern.

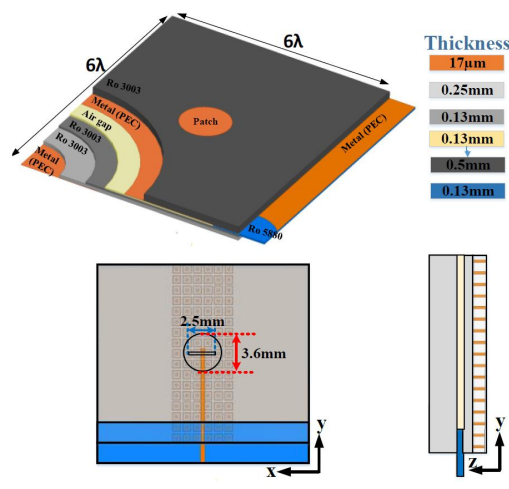

(a)
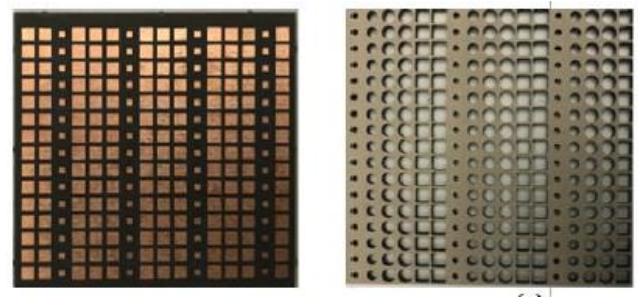

(b)

Figure 16. Configuration of a RCA with a tilted beam: (a) Main radiating element (PRGW); (b) Fabricated prototype of PGS and PDGS [139].

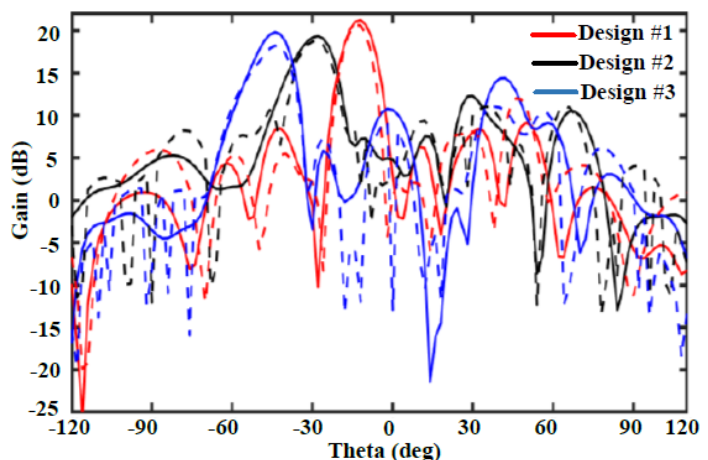

(a)

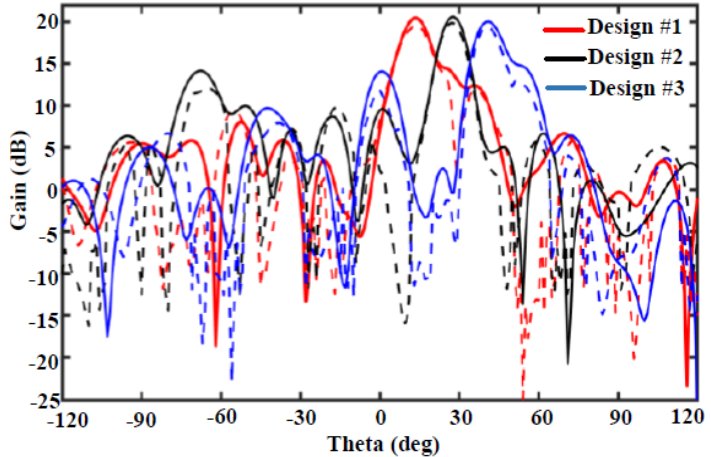

(b)

Figure 17. Simulated and measured results of the radiation patterns of the RCA in [139]: (a) PGS; (b) PDGSs configuration.

\subsection{Further Fields of Study: Low Profile and Multi-Band RCAs}

Reducing the total size of the RCAs, especially, the cavity height makes them more appealing for the future communication systems. Many works have been done to reduce the profile of RCAs [52,100,101,147-157]. Minimizing the cavity height so that the antenna performance does not have any degradation has been challenging. Based on the analytical models, the height of RCA structure is dependent on the sum of the reflection phase of the ground plane and PRS layer, which is approximately half of the wavelength. Consequently, a ground plane with zero reflection phase, which can be realized by employing high impedance surfaces (HIS) called artificial magnetic conductors (AMC) can minimize the cavity thickness. A compact multi-band high-gain RCA is presented in [156] using a FSS structure as ground plane with zero reflection phase. In some cases, using a ground plane 
with an associate reflection phase opposite to the PRS reflection phase sign shrinks the thickness of the cavity a lot [150]. In Reference [153], a miniaturized-element frequency selective surface (MEFSS) cover consisted of a PRS and HIS is proposed to improve the radiation gain of the antenna in chip while having a small cavity height. The MEFSS cover is designed to be placed on the chip to increase the antenna radiation performance in RFICs. As shown in Figure 18, the antenna radiation gain can be increased by $9 \mathrm{~dB}$ by placing the MEFSS cover on top of the antenna, while the cover is designed to have a very small cavity height by designing the PRS and HIS layers. A maximum gain of $14 \mathrm{dBi}$ with a cavity height of $\lambda / 30$ is achieved through using the proposed MEFSS. This antenna is applicable for radar and communication systems, as well as wireless sensor networks for the future 5G systems.

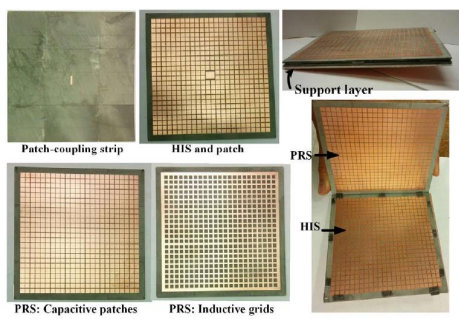

(a)

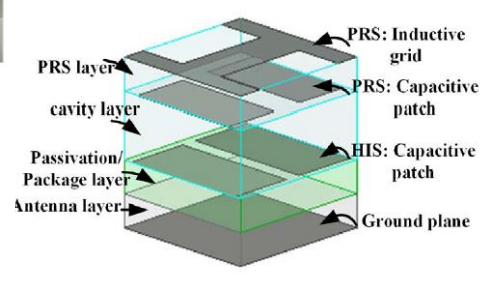

(b)

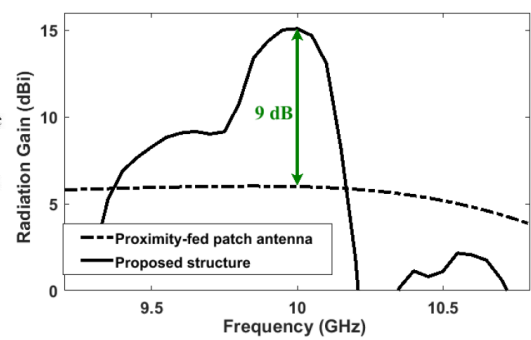

(c)

Figure 18. Configuration of the RCA in [153]: (a) Fabricated MEFSS cover; (b) MEFSS unit cell; (c) Radiation gain of the main radiator with and without MEFSS cover.

Multi-band high-gain antennas are highly required for the next communication systems. The capability of the RCA structures to possess the multi-band characteristic has been extensively investigated in the literature [156,158-163]. Generally, creating different resonances that satisfy the resonance conditions is the way to design multi-band RCAs. In Reference [159], a dual-band high-gain RCA with two vertical and horizontal polarizations is proposed. A dual-feed microstrip patch antenna is used as the main radiator, which has dual-band and dual-polarization characteristics. A PRS composed of double-layer orthogonal dipole arrays to create V-pol and H-pol is placed above the main radiator. The RPS unit cell is designed so that the resonance condition is satisfied over two different frequency bands with orthogonal polarizations in order to improve the radiation characteristic of the RCA. The configuration of the main radiator and PRS are shown in Figure 19. The lower band and upper band have a maximum gain of $19.6 \mathrm{dBi}$ and $18 \mathrm{dBi}$ at $10 \mathrm{GHz}$ and $11.6 \mathrm{GHz}$, respectively, as shown in Figure 20. The polarization of the RCA is vertical and horizontal at lower and upper frequency bands, respectively.

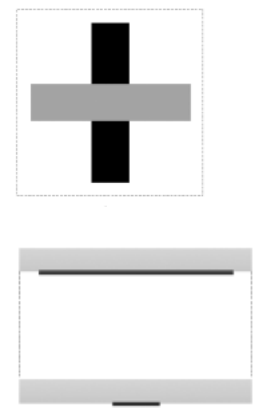

(a)

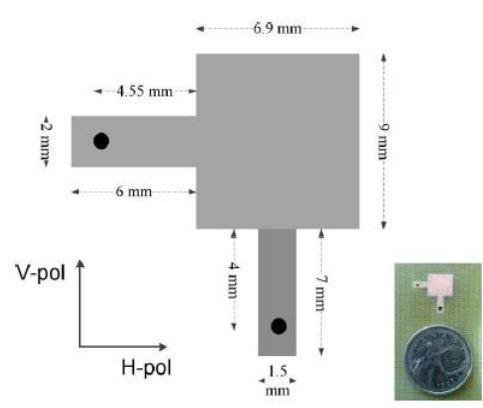

(b)

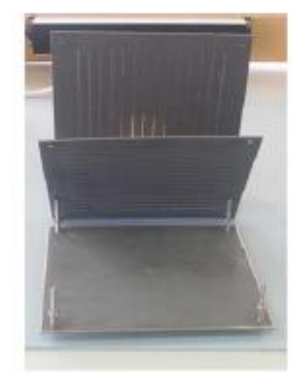

(c)

Figure 19. Configuration of the design in [159]: (a) Unit cell; (b) Main radiator; (c) Entire RCA structure.

Finaly, Table 1 lists some of the RCAs discussed in this paper to comprehensively summarize different works. The performance of the antennas in terms of maximum gain, overlapped bandwidth, 
operating frequency, polarization, reconfigurability, entire size, the height of cavity, and the number of PRSs used is demonstrated.

Table 1. Comparison between different RCAs.

\begin{tabular}{|c|c|c|c|c|c|c|c|c|}
\hline Ant & $\begin{array}{l}\text { Max-gain } \\
\text { (dB/dBic) }\end{array}$ & Pol. & Reconfigurability & $\begin{array}{l}\mathrm{f}_{\min } \\
(\mathrm{GHz})\end{array}$ & $\begin{array}{l}\text { Size } \\
\left(\lambda_{\min }\right)^{2}\end{array}$ & $\begin{array}{l}\mathbf{H} \\
\left(\lambda_{\min }\right)\end{array}$ & $\begin{array}{l}\text { BW } \\
(\%)\end{array}$ & $\begin{array}{l}\text { PRS } \\
\text { Layer } \\
\text { (\#) }\end{array}$ \\
\hline [58] & 17.2 & LP & - & 8.9 & $2.37 \times 2.37$ & 0.52 & 25.5 & 1 \\
\hline [61] & 12.5 & $\mathrm{CP}$ & - & 6.5 & $1.56 \times 1.56$ & 0.44 & 35.5 & 1 \\
\hline [67] & 15 & $\mathrm{CP}$ & - & 6 & $1.2 \times 1.2$ & 0.6 & 47.4 & 2 \\
\hline [68] & 13.5 & $\mathrm{CP}$ & - & 6 & $2 \times 2$ & 0.7 & 73.7 & 3 \\
\hline [93] & 15.5 & $\mathrm{CP}$ & - & 6.3 & $1.7 \times 1.7$ & 0.46 & 25.6 & 1 \\
\hline [96] & 11.45 & $\mathrm{CP}$ & - & 12.4 & $1.45 \times 1.45$ & 0.4 & 29.3 & 1 \\
\hline$[72]$ & 19.3 & $\mathrm{LP}$ & - & 10 & $2.5 \times 2.5$ & 0.4 & 51.8 & stair-case \\
\hline [65] & 16.8 & $\mathrm{LP}$ & - & 58.6 & $4.33 \times 3.52$ & 0.5 & 12.5 & 2 \\
\hline [74] & 19.5 & LP & - & 55.2 & $3.11 \times 3.11$ & 0.55 & 16.3 & stair-case \\
\hline [75] & 17.7 & LP & - & 12.2 & $4.32 \times 4.32$ & 1 & 25 & 1 \\
\hline [82] & 19 & $\mathrm{LP}$ & - & 10.3 & $3.95 \times 3.95$ & 0.5 & 9.4 & $\begin{array}{l}\text { one flat } \\
\text { and one } \\
\text { stair-case }\end{array}$ \\
\hline$[42]$ & 14.1 & $\mathrm{CP}$ & - & 26 & $1.58 \times 1.58$ & 0.7 & 18.5 & 1 \\
\hline [140] & 9.7 & LP & - pattern & 5.4 & $1.8 \times 1.8$ & 0.5 & 3.7 & 1 \\
\hline [109] & 10 & LP & - frequency & 5.2 & $4.16 \times 4.16$ & 0.4 & 13.4 & 1 \\
\hline [111] & 14.1 & LP & - frequency & 9.05 & $2.74 \times 2.74$ & 0.53 & 9.97 & 1 \\
\hline [114] & -- & LP & - beamwidth & 1.985 & $3.3 \times 3.3$ & 0.5 & 5 & 1 \\
\hline [125] & 14.1 & $\mathrm{LP} / \mathrm{CP}$ & - polarization & 9.6 & $2.83 \times 2.83$ & 1.06 & 6.7 & 3 \\
\hline [139] & 22 & LP & - pattern & 59 & $5.9 \times 5.9$ & 0.5 & 3.4 & 2 \\
\hline [115] & 14.7 & LP & - pattern & 1.97 & $2.26 \times 2.26$ & 0.51 & 3 & 1 \\
\hline [145] & 8 & LP & - pattern & 4.9 & $0.98 \times 1.1$ & 0.1 & 4 & 1 \\
\hline [153] & 14 & LP & -- & 9.94 & $3.2 \times 3.2$ & 0.03 & 2.97 & 1 \\
\hline [159] & $\begin{array}{l}19.6 \\
18\end{array}$ & $\begin{array}{l}\mathrm{LP}(\mathrm{V}) \\
\mathrm{LP}(\mathrm{H})\end{array}$ & -- & $\begin{array}{l}9.8 \\
11.4\end{array}$ & $\begin{array}{l}5 \times 5 \\
5.85 \times 5.85\end{array}$ & $\begin{array}{l}0.5 \\
0.6\end{array}$ & $\begin{array}{l}3 \\
2.56\end{array}$ & 2 \\
\hline
\end{tabular}

$f_{\min }$ is the minimum operation frequency. ' $\mathrm{H}$ ' is the height of the cavity which is the distance between the ground plane and the first layer of superstrates. BW is overlapped bandwidths of 3-dB AR, 3-dB gain, and $\left|S_{11}\right|$. 


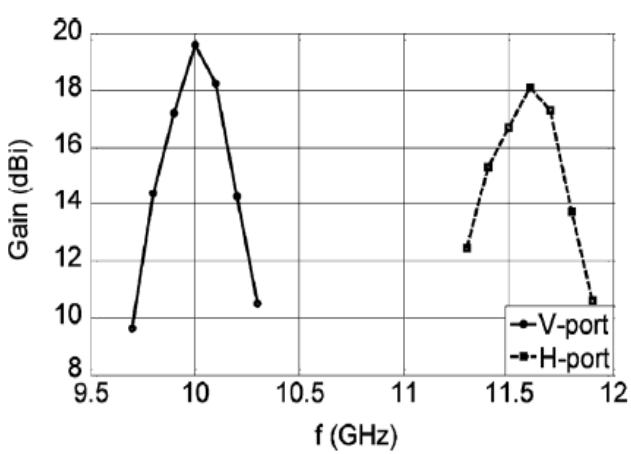

(a)

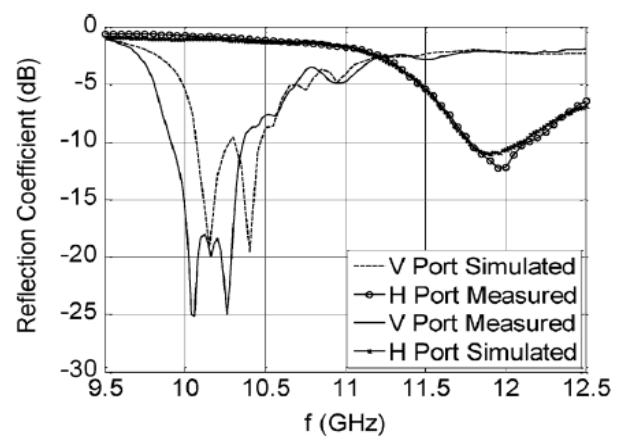

(b)

Figure 20. Results of the RCA in [159]: (a) Gain; (b) Reflection coefficient.

\section{Conclusions}

Since there is a high interest both in academia and industry for the high-gain antennas, this paper provides a comprehensive discussion on the RCAs in terms of their challenges, applications, and research trend. The RCAs owing to their advantages such as simple feed structure, planar configuration, high-gain, low-cost fabrication, and ease of integration with other systems are promising candidates to be used in the next communication systems.

The mechanism of the RCAs has been presented by different techniques; among them are ray tracing, TL, and LW models. The research fields of the RCAs were briefly discussed through demonstrating the practical examples and recent studies covering their low-profile, high aperture efficiency, wide 3-dB bandwidth, beam-steering and $\mathrm{CP}$ features and multi-beam and reconfigurability capabilities, especially in the millimeter-wave frequencies for future developments.

Having wider $3-\mathrm{dB}$ gain bandwidth is still challenging in the implementation of the RCAs. Efficient designs and techniques to make wider 3-dB gain bandwidth including using PRS unit cells with positive reflection phase gradient, sharp resonance, and non-uniform configurations were reviewed. Besides, the possibility to generate a wider 3-dB gain bandwidth by manipulating the configuration of the ground plane and PRS structures was briefly discussed.

Multi functional antennas are the desired solution for the 5G millimeter wave frequencies to avoid no extra equipment, which lead to bulky structures. Reconfigurability of RCAs offer altering operation frequency, polarization, radiation pattern, and beamwidth to address the potential problems of the next communication systems. Beam-steering and CP characteristics add more flexibility to the antennas to tolerate the environment issues and to have stable performance, as explained in this paper.

Multi-band and low-profile RCAs are attractive topics covered in this review paper. In order to decrease the cavity height, decreasing the sum value of reflection phase of the PRS unit cell and ground plane is required, which can be obtained by using AMC or HIS structures as the ground plane. It is explained that to design a multi-band RCA, it is required to create different resonances that satisfy the resonance condition, simultaneously.

In summary, it is the stable functionality and stunning performance of the RCAs over different frequency bands that make them attractive for the next generation wireless communication systems, i.e., fifth generation (5G).

Author Contributions: A.G. and M.M.H. prepared the first draft of the paper. A.G., M.M.H. and R.M. discussed the presentation development of the manuscript. A.G., M.M.H. and R.M. reviewed the manuscript. All authors have read and agreed to the published version of the manuscript

Funding: This research was supported by TELUS Communication Inc., Natural Sciences and Engineering Research Council of Canada (NSERC) and Alberta Innovate (AI) under NSERC-AITF industrial research chair program.

Conflicts of Interest: The authors declare no conflict of interest. 


\section{Abbreviations}

The following abbreviations are used in this manuscript:

5G Fifth-Generation

MMW Millimeter-Wave

RC Resonant Cavity

PRS Partially Reflective Surface

FPCA Fabry-Pérot Cavity Antenna

EBG Electromagnetic-Band-gap

LW Leaky- Wave

MTM Metamaterial

FSS Frequency Selective Surface

TPG Transverse Permitivity Gradient

GBP Gain-Bandwidth Product

FZP Fresnel Zone Plate

CP Circularly-Polarized

HIS High Impedance Surfaces

AMC Artificial Magnetic Conductors

FSS Frequency Selective Surface

PRGW Printed Ridge-Gap Waveguide

GSP Gridded Square Patch

SSLP Square Slot-Loaded Patch

WSDL Wedge-Shaped Dielectric Lens

DMGD Discrete Multilevel Grating Dielectric

PGS Printed Gradient Surface

PDGS Perforated Dielectric Gradient Surface

CM Characteristic Mode

MEFSS Miniaturized-Element Frequency Selective Surface

\section{References}

1. Thompson, J.; Ge, X.; Wu, H.C.; Irmer, R.; Jiang, H.; Fettweis, G.; Alamouti, S. 5G wireless communication systems: Prospects and challenges [Guest Editorial]. IEEE Commun. Mag. 2014, 52, 62-64. [CrossRef]

2. Rappaport, T.S.; Sun, S.; Mayzus, R.; Zhao, H.; Azar, Y.; Wang, K.; Wong, G.N.; Schulz, J.K.; Samimi, M.; Gutierrez, F. Millimeter wave mobile communications for 5G cellular: It will work! IEEE Access 2013, 1, 335-349. [CrossRef]

3. Honari, M.M.; Mirzavand, R.; Melzer, J.; Mousavi, P. A new aperture antenna using substrate integrated waveguide corrugated structures for 5G applications. IEEE Antennas Wirel. Propag. Lett. 2016, 16, $254-257$. [CrossRef]

4. Mahajan, M.; Jyoti, R.; Sood, K.; Sharma, S.B. A Method of Generating Simultaneous Contoured and Pencil Beams From Single Shaped Reflector Antenna. IEEE Trans. Antennas Propag. 2013, 61, 5297-5301. [CrossRef]

5. Deguchi, H.; Tsuji, M.; Shigesawa, H. Compact low-cross-polarization horn antennas with serpentine-shaped taper. IEEE Trans. Antennas Propag. 2004, 52, 2510-2516. [CrossRef]

6. Honari, M.M.; Abdipour, A.; Moradi, G. Aperture-coupled multi-layer broadband ring-patch antenna array. IEICE Electron. Expr. 2012, 9, 250-255. [CrossRef]

7. Cheng, Y.J.; Guo, Y.X.; Liu, Z.G. W-Band Large-Scale High-Gain Planar Integrated Antenna Array. IEEE Trans. Antennas Propag. 2014, 62, 3370-3373. [CrossRef]

8. Fan, C.; Yang, W.; Che, W.; He, S.; Xue, Q. A Wideband and Low-Profile Discrete Dielectric Lens Using 3-D Printing Technology. IEEE Trans. Antennas Propag. 2018, 66, 5160-5169. [CrossRef]

9. Honari, M.M.; Mirzavand, R.; Mousavi, P. A high-gain planar surface plasmon wave antenna based on substrate integrated waveguide technology with size reduction. IEEE Trans. Antennas Propag. 2018, 66, 2605-2609. [CrossRef]

10. Honari, M.M.; Sarabandi, K.; Mousavi, P. Dual-Band High-Gain Planar Corrugated Antennas with Integrated Feeding Structure. IEEE Access 2020, 8, 67075-67084. [CrossRef] 
11. Honari, M.M.; Sarabandi, K.; Mousavi, P. Design and Analysis of Corrugated Antennas Based on Surface Susceptance of a Single Cell of Corrugation. IEEE Trans. Antennas Propag. 2020. [CrossRef]

12. Amjadi, S.M.; Sarabandi, K. A low-profile, high-gain, and full-band subarray of cavity-backed slot antenna. IEEE Trans. Antennas Propag. 2017, 65, 3456-3464. [CrossRef]

13. Guan, D.F.; Ding, C.; Qian, Z.P.; Zhang, Y.S.; Guo, Y.J.; Gong, K. Broadband high-gain SIW cavity-backed circular-polarized array antenna. IEEE Trans. Antennas Propag. 2016, 64, 1493-1497. [CrossRef]

14. Yang, D.; Cao, F.; Pan, J. A single-layer dual-frequency shared-aperture SIW slot antenna array with a small frequency ratio. IEEE Antennas Wirel. Propag. Lett. 2018, 17, 1048-1051. [CrossRef]

15. Honari, M.M.; Mirzavand, R.; Saghlatoon, H.; Mousavi, P. A dual-band low-profile aperture antenna with substrate-integrated waveguide grooves. IEEE Trans. Antennas Propag. 2016, 64, 1561-1566. [CrossRef]

16. Mirzavand, R.; Honari, M.M.; Mousavi, P. Direct-Conversion Sensor for Wireless Sensing Networks. IEEE Trans. Ind. Electron. 2017, 64, 9675-9682. [CrossRef]

17. Saghlatoon, H.; Mirzavand, R.; Honari, M.M.; Mousavi, P. Sensor Antenna Transmitter System for Material Detection in Wireless-Sensor-Node Applications. IEEE Sens. J. 2018, 18, 8812-8819. [CrossRef]

18. Khalid, N.; Mirzavand, R.; Saghlatoon, H.; Honari, M.M.; Mousavi, P. A Three-Port Zero-Power RFID Sensor Architecture for IoT Applications. IEEE Access 2020, 8, 66888-66897. [CrossRef]

19. Mirzavand, R.; Honari, M.M.; Laribi, B.; Khorshidi, B.; Sadrzadeh, M.; Mousavi, P. An unpowered sensor node for real-time water quality assessment (humic acid detection). Electronics 2018, 7, 231. [CrossRef]

20. Mirzavand, R.; Honari, M.M.; Mousavi, P. High-resolution dielectric sensor based on injection-locked oscillators. IEEE Sens. J. 2017, 18, 141-148. [CrossRef]

21. Trentini, G.V. Partially reflecting sheet arrays. IRE Trans. Antennas Propag. 1956, 4, 666-671. [CrossRef]

22. Jackson, D.; Alexopoulos, N. Gain enhancement methods for printed circuit antennas. IEEE Trans. Antennas Propag. 1985, 33, 976-987. [CrossRef]

23. Yang, H.; Alexopoulos, N. Gain enhancement methods for printed circuit antennas through multiple superstrates. IEEE Trans. Antennas Propag. 1987, 35, 860-863. [CrossRef]

24. Jackson, D.R.; Oliner, A.A. A leaky-wave analysis of the high-gain printed antenna configuration. IEEE Trans. Antennas Propag. 1988, 36, 905-910. [CrossRef]

25. Jackson, D.; Oliner, A.; Ip, A. Leaky-wave propagation and radiation for a narrow-beam multiple-layer dielectric structure. IEEE Trans. Antennas Propag. 1993, 41, 344-348. [CrossRef]

26. James, J.; Kinany, S.; Peel, P.; Andrasic, G. Leaky-wave multiple dichroic beamformers. Electron. Lett. 1989, 25, 1209-1211. [CrossRef]

27. Leger, L.; Monediere, T.; Jecko, B. Enhancement of gain and radiation bandwidth for a planar 1-D EBG antenna. IEEE Microw. Wirel. Compon. Lett. 2005, 15, 573-575. [CrossRef]

28. Hashmi, R.M.; Esselle, K.P. A wideband EBG resonator antenna with an extremely small footprint area. Microw. Opt. Technol. Lett. 2015, 57, 1531-1535. [CrossRef]

29. Meng, F.; Sharma, S.K. A Wideband Resonant Cavity Antenna with Compact Partially Reflective Surface. IEEE Trans. Antennas Propag. 2020, 68, 1155-1160. [CrossRef]

30. Zhao, T.; Jackson, D.R.; Williams, J.T.; Yang, H.Y.; Oliner, A.A. 2-D periodic leaky-wave antennas-part I: Metal patch design. IEEE Trans. Antennas Propag. 2005, 53, 3505-3514. [CrossRef]

31. Zhao, T.; Jackson, D.R.; Williams, J.T. 2-D periodic leaky-wave Antennas-part II: Slot design. IEEE Trans. Antennas Propag. 2005, 53, 3515-3524. [CrossRef]

32. Baba, A.A.; Hashmi, R.M.; Esselle, K.P.; Marin, J.G.; Hesselbarth, J. Broadband Partially Reflecting Superstrate-Based Antenna for $60 \mathrm{GHz}$ Applications. IEEE Trans. Antennas Propag. 2019, 67, 4854-4859. [CrossRef]

33. Vaidya, A.R.; Gupta, R.K.; Mishra, S.K.; Mukherjee, J. High-gain low side lobe level Fabry Perot cavity antenna with feed patch array. Prog. Electromagn. Res. C 2012, 28, 223-238. [CrossRef]

34. Sengupta, S.; Jackson, D.R.; Almutawa, A.T.; Kazemi, H.; Capolino, F.; Long, S.A. A Cross-Shaped 2D Periodic Leaky-Wave Antenna. IEEE Trans. Antennas Propag. 2019. [CrossRef]

35. Zhao, T.; Jackson, D.R.; Williams, J.T.; Oliner, A.A. General formulas for 2-D leaky-wave antennas. IEEE Trans. Antennas Propag. 2005, 53, 3525-3533. [CrossRef]

36. Lovat, G.; Burghignoli, P.; Capolino, F.; Jackson, D. Highly-directive planar leaky-wave antennas: A comparison between metamaterial-based and conventional designs. Proc. EuMA 2006, 2, 12-21. 
37. Lovat, G.; Burghignoli, P.; Jackson, D.R. Fundamental properties and optimization of broadside radiation from uniform leaky-wave antennas. IEEE Trans. Antennas Propag. 2006, 54, 1442-1452. [CrossRef]

38. Foroozesh, A.; Shafai, L. Investigation into the effects of the patch-type FSS superstrate on the high-gain cavity resonance antenna design. IEEE Trans. Antennas Propag. 2009, 58, 258-270. [CrossRef]

39. Sengupta, S.; Jackson, D.; Long, S. Modal Analysis and Propagation Characteristics of Leaky Waves on a 2-D Periodic Leaky-Wave Antenna. IEEE Trans. Microw. Theory Tech. 2018, 1-11. [CrossRef]

40. Almutawa, A.T.; Hosseini, A.; Jackson, D.R.; Capolino, F. Leaky-Wave Analysis of Wideband Planar Fabry-Pérot Cavity Antennas Formed by a Thick PRS. IEEE Trans. Antennas Propag. 2019, 67, 5163-5175. [CrossRef]

41. Almutawa, A.T.; Capolino, F.; Jackson, D.R. Overview of Wideband Fabry-Perot Cavity Antennas with Thick Partially Reflective Surface. In Proceedings of the 2019 International Conference on Electromagnetics in Advanced Applications (ICEAA), Granada, Spain, 9-13 September 2019; pp. 1308-1310.

42. Hussain, N.; Jeong, M.; Park, J.; Kim, N. A Broadband Circularly Polarized Fabry-Perot Resonant Antenna Using A Single-Layered PRS for 5G MIMO Applications. IEEE Access 2019, 7, 42897-42907. [CrossRef]

43. Gardelli, R.; Albani, M.; Capolino, F. Array thinning by using antennas in a Fabry-Perot cavity for gain enhancement. IEEE Trans. Antennas Propag. 2006, 54, 1979-1990. [CrossRef]

44. Boutayeb, H.; Denidni, T.A. Internally excited Fabry-Perot type cavity: Power normalization and directivity evaluation. IEEE Antennas Wirel. Propag. Lett. 2006, 5, 159-162. [CrossRef]

45. Liu, Z.G.; Guo, Y.X. Effect of primary source location on fabry-perot resonator antenna with PEC or PMC ground plate. J. Infrared Millim. Terahertz Waves 2010, 31, 1022-1031. [CrossRef]

46. Hashmi, R.M.; Esselle, K.P. Enhancing the performance of EBG resonator antennas by individually truncating the superstructure layers. IET Microw. Antennas Propag. 2016, 10, 1048-1055. [CrossRef]

47. Feresidis, A.P.; Vardaxoglou, J. High gain planar antenna using optimised partially reflective surfaces. IEE Proc. Microw. Anten. Propag. 2001, 148, 345-350. [CrossRef]

48. Ge, Y.; Esselle, K.P.; Bird, T.S. The use of simple thin partially reflective surfaces with positive reflection phase gradients to design wideband, low-profile EBG resonator antennas. IEEE Trans. Antennas Propag. 2011, 60, 743-750. [CrossRef]

49. Mateo-Segura, C.; Feresidis, A.P.; Goussetis, G. Bandwidth enhancement of 2-D leaky-wave antennas with double-layer periodic surfaces. IEEE Trans. Antennas Propag. 2013, 62, 586-593. [CrossRef]

50. Al-Tarifi, M.A.; Anagnostou, D.E.; Amert, A.K.; Whites, K.W. Bandwidth enhancement of the resonant cavity antenna by using two dielectric superstrates. IEEE Trans. Antennas Propag. 2013, 61, 1898-1908. [CrossRef]

51. Wang, N.; Li, J.; Wei, G.; Talbi, L.; Zeng, Q.; Xu, J. Wideband Fabry-Perot resonator antenna with two layers of dielectric superstrates. IEEE Antennas Wirel. Propag. Lett. 2014, 14, 229-232. [CrossRef]

52. Konstantinidis, K.; Feresidis, A.P.; Hall, P.S. Broadband sub-wavelength profile high-gain antennas based on multi-layer metasurfaces. IEEE Trans. Antennas Propag. 2014, 63, 423-427. [CrossRef]

53. Konstantinidis, K.; Feresidis, A.P.; Hall, P.S. Multilayer partially reflective surfaces for broadband Fabry-Perot cavity antennas. IEEE Trans. Antennas Propag. 2014, 62, 3474-3481. [CrossRef]

54. Hashmi, R.M.; Zeb, B.A.; Esselle, K.P. Wideband high-gain EBG resonator antennas with small footprints and all-dielectric superstructures. IEEE Trans. Antennas Propag. 2014, 62, 2970-2977. [CrossRef]

55. Wang, N.; Talbi, L.; Zeng, Q.; Xu, J. Wideband Fabry-Perot resonator antenna with electrically thin dielectric superstrates. IEEE Access 2018, 6, 14966-14973. [CrossRef]

56. Nguyen-Trong, N.; Tran, H.H.; Nguyen, T.K.; Abbosh, A.M. Wideband Fabry-Perot antennas employing multilayer of closely spaced thin dielectric slabs. IEEE Antennas Wirel. Propag. Lett. 2018, 17, 1354-1358. [CrossRef]

57. Zeb, B.; Hashmi, R.; Esselle, K. Wideband gain enhancement of slot antenna using one unprinted dielectric superstrate. Electron. Lett. 2015, 51, 1146-1148. [CrossRef]

58. Liu, Z.; Liu, S.; Bornemann, J.; Zhao, X.; Kong, X.; Huang, Z.; Bian, B.; Wang, D. A Low-RCS, High-GBP Fabry-Perot Antenna With Embedded Chessboard Polarization Conversion Metasurface. IEEE Access 2020, 8, 80183-80194. [CrossRef]

59. Wang, N.; Liu, Q.; Wu, C.; Talbi, L.; Zeng, Q.; Xu, J. Wideband Fabry-Perot resonator antenna with two complementary FSS layers. IEEE Trans. Antennas Propag. 2014, 62, 2463-2471.

60. Ge, Y.; Sun, Z.; Chen, Z.; Chen, Y.Y. A high-gain wideband low-profile Fabry-Pérot resonator antenna with a conical short horn. IEEE Antennas Wirel. Propag. Lett. 2016, 15, 1889-1892. [CrossRef] 
61. Goudarzi, A.; Movahhedi, M.; Honari, M.M.; Saghlatoon, H.; Mirzavand, R.; Mousavi, P. Wideband HighGain Circularly Polarized Resonant Cavity Antenna with a Thin Complementary Partially Reflective Surface. IEEE Trans. Antennas Propag. 2020, 1-6, [CrossRef]

62. Goudarzi, A.; Movahhedi, M.; Honari, M.M.; Mousavi, P. A Wideband CP Resonant Cavity Antenna with a Self-Complimentary Partially Reflective Surface. In Proceedings of the 2020 IEEE AP-S Symposium on Antennas and Propagatio, Montréal, QC, Canada, 5-10 July 2020.

63. Ge, Y.; Wang, C. A millimeter-wave wideband high-gain antenna based on the fabry-perot resonator antenna concept. PIER C 2014, 50, 103-111. [CrossRef]

64. Han, W.; Yang, F.; Ouyang, J.; Yang, P. Low-cost wideband and high-gain slotted cavity antenna using high-order modes for millimeter-wave application. IEEE Trans. Antennas Propag. 2015, 63, 4624-4631. [CrossRef]

65. Attia, H.; Abdelghani, M.L.; Denidni, T.A. Wideband and high-gain millimeter-wave antenna based on FSS Fabry-Perot cavity. IEEE Trans. Antennas Propag. 2017, 65, 5589-5594. [CrossRef]

66. Singh, A.K.; Abegaonkar, M.P.; Koul, S.K. High-gain and high-aperture-efficiency cavity resonator antenna using metamaterial superstrate. IEEE Antennas Wirel. Propag. Lett. 2017, 16, 2388-2391. [CrossRef]

67. Nguyen-Trong, N.; Tran, H.H.; Nguyen, T.K.; Abbosh, A.M. A compact wideband circular polarized Fabry-Perot antenna using resonance structure of thin dielectric slabs. IEEE Access 2018, 6, 56333-56339. [CrossRef]

68. Tran, H.H.; Le, T.T.; Bui, C.D.; Nguyen, T.K. Broadband circularly polarized Fabry-Perot antenna utilizing Archimedean spiral radiator and multi-layer partially reflecting surface. Int. J. RF Microw. Comput.-Aided Eng. 2019, 29, e21647. [CrossRef]

69. Hashmi, R.M.; Esselle, K.P. A class of extremely wideband resonant cavity antennas with large directivitybandwidth products. IEEE Trans. Antennas Propag. 2015, 64, 830-835. [CrossRef]

70. Baba, A.; Hashmi, R.; Esselle, K. Wideband gain enhancement of slot antenna using superstructure with optimised axial permittivity variation. Electron. Lett. 2016, 52, 266-268. [CrossRef]

71. Baba, A.A.; Hashmi, R.M.; Esselle, K.P. Achieving a large gain-bandwidth product from a compact antenna. IEEE Trans. Antennas Propag. 2017, 65, 3437-3446. [CrossRef]

72. Baba, A.A.; Hashmi, R.M.; Esselle, K.P.; Weily, A.R. Compact high-gain antenna with simple all-dielectric partially reflecting surface. IEEE Trans. Antennas Propag. 2018, 66, 4343-4348. [CrossRef]

73. Baba, A.A.; Hashmi, R.M.; Asadnia, M.; Matekovits, L.; Esselle, K.P. A Stripline-Based Planar Wideband Feed for High-Gain Antennas with Partially Reflecting Superstructure. Micromachines 2019, 10, 308. [CrossRef] [PubMed]

74. Baba, A.A.; Hashmi, R.M.; Esselle, K.P.; Ahmad, Z.; Hesselbarth, J. Millimeter-Wave Broadband Antennas with Low Profile Dielectric Covers. IEEE Access 2019. [CrossRef]

75. Wu, F.; Luk, K.M. Wideband high-gain open resonator antenna using a spherically modified, second-order cavity. IEEE Trans. Antennas Propag. 2017, 65, 2112-2116. [CrossRef]

76. Chen, Q.; Chen, X.; Xu, K. 3-D printed Fabry-Perot resonator antenna with paraboloid-shape superstrate for wide gain bandwidth. Appl. Sci. 2017, 7, 1134. [CrossRef]

77. Ji, L.Y.; Qin, P.Y.; Guo, Y.J. Wideband Fabry-Perot cavity antenna with a shaped ground plane. IEEE Access 2017, 6, 2291-2297. [CrossRef]

78. Qing-Yi, G.; Hang, W. A Fabry-Pérot Cavity Antenna for Millimeter-Wave Application. In Proceedings of the 2019 Cross Strait Quad-Regional Radio Science and Wireless Technology Conference (CSQRWC), Taiyuan, China, 18-21 July 2019; pp. 1-2.

79. Guo, Q.Y.; Wong, H. A Millimeter-Wave Fabry-Pérot Cavity Antenna Using Fresnel Zone Plate Integrated PRS. IEEE Trans. Antennas Propag. 2019, 68, 564-568. [CrossRef]

80. Weily, A.R.; Esselle, K.; Bird, T.S.; Sanders, B.C. Dual resonator 1-D EBG antenna with slot array feed for improved radiation bandwidth. IET Microw. Antennas Propag. 2007, 1, 198-203. [CrossRef]

81. Afzal, M.U.; Esselle, K.P.; Lalbakhsh, A. A methodology to design a low-profile composite-dielectric phase-correcting structure. IEEE Antennas Wirel. Propag. Lett. 2018, 17, 1223-1227. [CrossRef]

82. Hayat, T.; Afzal, M.U.; Lalbakhsh, A.; Esselle, K.P. 3-D-printed phase-rectifying transparent superstrate for resonant-cavity antenna. IEEE Antennas Wirel. Propag. Lett. 2019, 18, 1400-1404. [CrossRef] 
83. Hayat, T.; Afzal, M.U.; Lalbakhsh, A.; Esselle, K.P. Additively Manufactured Perforated Superstrate to Improve Directive Radiation Characteristics of Electromagnetic Source. IEEE Access 2019, 7, 153445-153452. [CrossRef]

84. Xie, P.; Wang, G.; Li, H.; Gao, X. A Novel Methodology for Gain Enhancement of the Fabry-Pérot Antenna. IEEE Access 2019, 7, 176170-176176. [CrossRef]

85. Zhou, L.; Duan, X.; Luo, Z.; Zhou, Y.; Chen, X. High Directivity Fabry-Perot Antenna with a Nonuniform Partially Reflective Surface and a Phase Correcting Structure. IEEE Trans. Antennas Propag. 2020. [CrossRef]

86. Zhou, L.; Chen, X.; Duan, X. Fabry-Pérot resonator antenna with high aperture efficiency using a double-layer nonuniform superstrate. IEEE Trans. Antennas Propag. 2018, 66, 2061-2066. [CrossRef]

87. Lalbakhsh, A.; Afzal, M.U.; Esselle, K.P.; Smith, S.L.; Zeb, B.A. Single-dielectric wideband partially reflecting surface with variable reflection components for realization of a compact high-gain resonant cavity antenna. IEEE Trans. Antennas Propag. 2019, 67, 1916-1921. [CrossRef]

88. Lalbakhsh, A.; Afzal, M.U.; Esselle, K.P.; Smith, S.L. Wideband near-field correction of a Fabry-Perot resonator antenna. IEEE Trans. Antennas Propag. 2019, 67, 1975-1980. [CrossRef]

89. Ge, Y.; Esselle, K.P.; Hao, Y. Design of low-profile high-gain EBG resonator antennas using a genetic algorithm. IEEE Antennas Wirel. Propag. Lett. 2007, 6, 480-483. [CrossRef]

90. Zheng, Y.; Gao, J.; Zhou, Y.; Cao, X.; Yang, H.; Li, S.; Li, T. Wideband gain enhancement and RCS reduction of Fabry-Perot resonator antenna with chessboard arranged metamaterial superstrate. IEEE Trans. Antennas Propag. 2017, 66, 590-599. [CrossRef]

91. Qin, F.; Gao, S.; Wei, G.; Luo, Q.; Mao, C.; Gu, C.; Xu, J.; Li, J. Wideband circularly polarized Fabry-Perot antenna [antenna applications corner]. IEEE Antennas Propag. Mag. 2015, 57, 127-135. [CrossRef]

92. Ratni, B.; De Lustrac, A.; Villers, S.; Nawaz Burokur, S. Low-profile circularly polarized fabry-perot cavity antenna. Microw. Opt. Tech. Lett. 2016, 58, 2957-2960. [CrossRef]

93. Tran, H.H.; Park, I. Compact wideband circularly polarised resonant cavity antenna using a single dielectric superstrate. IET Microw. Antenna Propag. 2016, 10, 729-736. [CrossRef]

94. Ta, S.; Nguyen, T. AR bandwidth and gain enhancements of patch antenna using single dielectric superstrate. Electron. Lett. 2017, 53, 1015-1017. [CrossRef]

95. Ta, S.X.; Nguyen, T.H.Y.; Nguyen, K.K.; Dao-Ngoc, C. Bandwidth-enhancement of circularly-polarized fabryperot antenna using single-layer partially reflective surface. Int. J. RF Microw. Comput. Aided Eng. 2019, e21774. [CrossRef]

96. Cao, W.; Lv, X.; Wang, Q.; Zhao, Y.; Yang, X. Wideband circularly polarized Fabry-Pérot resonator antenna in Ku-band. IEEE Antennas Wirel. Propag. Lett. 2019, 18, 586-590. [CrossRef]

97. Cheng, Y.; Dong, Y. Bandwidth Enhanced Circularly Polarized Fabry-Perot Cavity Antenna Using Metal Strips. IEEE Access 2020, 60189-60198. [CrossRef]

98. Diblanc, M.; Rodes, E.; Arnaud, E.; Thevenot, M.; Monediere, T.; Jecko, B. Circularly polarized metallic EBG antenna. IEEE Microw. Wirel. Compon. Lett. 2005, 15, 638-640. [CrossRef]

99. Ju, J.; Kim, D.; Lee, W.; Choi, J. Design Method of a Circularly-Polarized Antenna Using Fabry-Pérot Cavity Structure. ETRI J. 2011, 33, 163-168. [CrossRef]

100. Orr, R.; Goussetis, G.; Fusco, V. Design method for circularly polarized Fabry-Perot cavity antennas. IEEE Trans. Antennas Propag. 2014, 62, 19-26. [CrossRef]

101. Liu, Z.G.; Lu, W.B. Low-profile design of broadband high gain circularly polarized Fabry-Perot resonator antenna and its array with linearly polarized feed. IEEE Access 2017, 5, 7164-7172. [CrossRef]

102. Srivastava, K.; Kumar, A.; Chaudhary, P.; Kanaujia, B.K.; Dwari, S.; Verma, A.K.; Esselle, K.P.; Mittra, R. Wideband and high-gain circularly polarised microstrip antenna design using sandwiched metasurfaces and partially reflecting surface. IET Microw. Antenna Propag. 2018, 13, 305-312. [CrossRef]

103. Muhammad, S.A.; Sauleau, R.; Valerio, G.; Le Coq, L.; Legay, H. Self-polarizing Fabry-Perot antennas based on polarization twisting element. IEEE Trans. Antennas Propag. 2012, 61, 1032-1040. [CrossRef]

104. Arnaud, E.; Chantalat, R.; Monédière, T.; Rodes, E.; Thevenot, M. Performance enhancement of self-polarizing metallic EBG antennas. IEEE Antennas Wirel. Propag. Lett. 2010, 9, 538-541. [CrossRef]

105. Hussain, N.; Jeong, M.J.; Abbas, A.; Kim, T.J.; Kim, N. A Metasurface-Based Low-Profile Wideband Circularly Polarized Patch Antenna for 5G Millimeter-Wave Systems. IEEE Access 2020, 8, 22127-22135. [CrossRef]

106. Lin, X.; Seet, B.C.; Joseph, F.; Li, E. Flexible fractal electromagnetic bandgap for millimeter-wave wearable antennas. IEEE Antennas Wirel. Propag. Lett. 2018, 17, 1281-1285. [CrossRef] 
107. Tang, M.C.; Shi, T.; Ziolkowski, R.W. A Study of 28 GHz, Planar, multilayered, electrically small, broadside radiating, huygens source antennas. IEEE Trans. Antennas Propag. 2017, 65, 6345-6354. [CrossRef]

108. Ourir, A.; Burokur, S.; de Lustrac, A. Electronically reconfigurable metamaterial for compact directive cavity antennas. Electron. Lett. 2007, 43, 698-700. [CrossRef]

109. Weily, A.R.; Bird, T.S.; Guo, Y.J. A reconfigurable high-gain partially reflecting surface antenna. IEEE Trans. Antennas Propag. 2008, 56, 3382-3390. [CrossRef]

110. Burokur, S.; Daniel, J.P.; Ratajczak, P.; De Lustrac, A. Tunable bilayered metasurface for frequency reconfigurable directive emissions. Appl. Phys. Lett. 2010, 97, 064101. [CrossRef]

111. Huang, C.; Pan, W.; Ma, X.; Luo, X. A frequency reconfigurable directive antenna with wideband low-RCS property. IEEE Trans. Antennas Propag. 2016, 64, 1173-1178. [CrossRef]

112. Xie, P.; Wang, G.M. Design of a frequency reconfigurable Fabry-Pérot cavity antenna with single layer partially reflecting surface. Prog. Electromagn. Res. 2017, 70, 115-121. [CrossRef]

113. Edalati, A.; Denidni, T.A. Reconfigurable beamwidth antenna based on active partially reflective surfaces. IEEE Antennas Wirel. Propag. Lett. 2009, 8, 1087-1090. [CrossRef]

114. Debogovic, T.; Perruisseau-Carrier, J.; Bartolic, J. Partially reflective surface antenna with dynamic beamwidth control. IEEE Antennas Wirel. Propag. Lett. 2010, 9, 1157-1160. [CrossRef]

115. Debogović, T.; Perruisseau-Carrier, J. Array-fed partially reflective surface antenna with independent scanning and beamwidth dynamic control. IEEE Trans. Antennas Propag. 2013, 62, 446-449. [CrossRef]

116. Vaidya, A.R.; Gupta, R.K.; Mishra, S.K.; Mukherjee, J. Right-hand/left-hand circularly polarized high-gain antennas using partially reflective surfaces. IEEE Antennas Wirel. Propag. Lett. 2014, 13, 431-434. [CrossRef]

117. Tan, G.N.; Yang, X.; Xue, H.G.; Lu, Z. A dual-polarized Fabry-Perot cavity antenna at Ka band with broadband and high gain. Prog. Electromagnet. Res. 2015, 60, 179-186. [CrossRef]

118. Lian, R.; Tang, Z.; Yin, Y. Design of a broadband polarization-reconfigurable Fabry-Perot resonator antenna. IEEE Antennas Wirel. Propag. Lett. 2017, 17, 122-125. [CrossRef]

119. Qin, P.Y.; Ji, L.Y.; Chen, S.L.; Guo, Y.J. Dual-polarized wideband Fabry-Perot antenna with quad-layer partially reflective surface. IEEE Antennas Wirel. Propag. Lett. 2018, 17, 551-554. [CrossRef]

120. Zhu, H.; Qiu, Y.; Wei, G. A Broadband Dual-Polarized Antenna with Low Profile Using Nonuniform Metasurface. IEEE Antennas Wirel. Propag. Lett. 2019, 18, 1134-1138. [CrossRef]

121. Wu, Z.; Liu, H.; Li, L. Metasurface-inspired low profile polarization reconfigurable antenna with simple DC controlling circuit. IEEE Access 2019, 7, 45073-45079. [CrossRef]

122. Liu, P.; Jiang, W.; Sun, S.; Xi, Y.; Gong, S. Broadband and Low-Profile Penta-Polarization Reconfigurable Metamaterial Antenna. IEEE Access 2020, 8, 21823-21831. [CrossRef]

123. Comite, D.; Baccarelli, P.; Burghignoli, P.; Galli, A. Omnidirectional 2-D leaky-wave antennas with reconfigurable polarization. IEEE Antennas Wirel. Propag. Lett. 2017, 16, 2354-2357. [CrossRef]

124. Chen, C.; Liu, Z.G.; Wang, H.; Guo, Y. Metamaterial-inspired self-polarizing dual-band dual-orthogonal circularly polarized Fabry-Pérot resonator antennas. IEEE Trans. Antennas Propag. 2018, 67, 1329-1334. [CrossRef]

125. Wu, F.; Luk, K.M. Circular Polarization and Reconfigurability of Fabry-Pérot Resonator Antenna Through Metamaterial-Loaded Cavity. IEEE Trans. Antennas Propag. 2019, 67, 2196-2208. [CrossRef]

126. Niaz, M.W.; Yin, Y.; Zheng, S.; Zhao, Z. Dual-polarized low sidelobe Fabry-Perot antenna using tapered partially reflective surface. Int. J. RF Microw. Comput.-Aided Eng. 2019, e22070. [CrossRef]

127. Swain, R.; Chatterjee, A.; Nanda, S.; Mishra, R.K. A Linear-to-Circular Polarization Conversion Metasurface Based Wideband Aperture Coupled Antenna. J. Electr. Eng. Technol. 2020, 1-7. [CrossRef]

128. Ourir, A.; Burokur, S.; de Lustrac, A. Passive and active reconfigurable resonant metamaterial cavity for beam deflection. In Proceedings of the 2007 IEEE Antennas and Propagation Society International Symposium, Honolulu, HI, USA, 9-15 June 2007; pp. 4973-4976.

129. Ourir, A.; Burokur, S.N.; Yahiaoui, R.; de Lustrac, A. Directive metamaterial-based subwavelength resonant cavity antennas-Applications for beam steering. C.R. Phys. 2009, 10, 414-422. [CrossRef]

130. Edalati, A.; Denidni, T.A. High-gain reconfigurable sectoral antenna using an active cylindrical FSS structure. IEEE Trans. Antennas Propag. 2011, 59, 2464-2472. [CrossRef]

131. Guo, Y.J.; Gómez-Tornero, J.L. Reconfigurable Fabry-Perot leaky-wave antennas. In Proceedings of the 2013 International Workshop on Antenna Technology (iWAT), Karlsruhe, Germany, 4-6 March 2013; pp. 390-393. 
132. Ji, L.Y.; Guo, Y.J.; Qin, P.Y.; Gong, S.X.; Mittra, R. A reconfigurable partially reflective surface (PRS) antenna for beam steering. IEEE Trans. Antennas Propag. 2015, 63, 2387-2395. [CrossRef]

133. Afzal, M.U.; Esselle, K.P. Steering the Beam of Medium-to-High Gain Antennas Using Near-Field Phase Transformation. IEEE Trans. Antennas Propag. 2017, 65, 1680-1690. [CrossRef]

134. Singh, K.; Afzal, M.U.; Kovaleva, M.; Esselle, K.P. Controlling the Most Significant Grating Lobes in Two-Dimensional Beam-Steering Systems with Phase-Gradient Metasurfaces. IEEE Trans. Antennas Propag. 2019, 68, 1389-1401.

135. Ji, L.Y.; Qin, P.Y.; Li, J.Y.; Zhang, L.X. 1-D Electronic Beam-Steering Partially Reflective Surface Antenna. IEEE Access 2019, 7, 115959-115965. [CrossRef]

136. Ji, L.Y.; Zhang, Z.Y.; Liu, N.W. A two-dimensional beam-steering partially reflective surface (PRS) antenna using a reconfigurable FSS structure. IEEE Antennas Wirel. Propag. Lett. 2019, 18, 1076-1080. [CrossRef]

137. Ji, L.Y.; Fu, S.; Zhang, L.X.; Li, J.Y. One-dimensional beam-steering Fabry-Perot cavity (FPC) antenna with a reconfigurable superstrate. Int. J. Microw. Wirel. Technol. 2020, 12, 233-239. [CrossRef]

138. Das, P.; Mandal, K.; Lalbakhsh, A. Single-layer polarization-insensitive frequency selective surface for beam reconfigurability of monopole antennas. J. Electromagnet. Waves Appl. 2020, 34, 86-102. [CrossRef]

139. Akbari, M.; Farahani, M.; Ghayekhloo, A.; Zarbakhsh, S.; Sebak, A.R.; Denidni, T. Phase Gradient Surface Approaches for $60 \mathrm{GHz}$ Beam Tilting Antenna. IEEE Trans. Antennas Propag. 2020, 68, 4372-4385.

140. Xie, P.; Wang, G.; Li, H.; Liang, J. A dual-polarized two-dimensional beam-steering Fabry-Pérot cavity antenna with a reconfigurable partially reflecting surface. IEEE Antennas Wirel. Propag. Lett. 2017, 16, 2370-2374. [CrossRef]

141. Ji, L.; Fu, G.; Gong, S.X. Array-fed beam-scanning partially reflective surface (PRS) antenna. Prog. Electromagnet. Res. 2016, 58, 73-79. [CrossRef]

142. Guo, Q.Y.; Wong, H. Wideband and high-gain Fabry-Pérot cavity antenna with switched beams for millimeter-wave applications. IEEE Trans. Antennas Propag. 2019, 67, 4339-4347. [CrossRef]

143. Tran, H.H.; Le, T.T. A metasurface based low-profile reconfigurable antenna with pattern diversity. AEU Int. J. Electron. Commun. 2020, 115, 153037. [CrossRef]

144. Guzmán-Quirós, R.; Weily, A.; Gómez-Tornero, J.; Guo, Y. A Fabry-Pérot antenna with two-dimensional electronic beam scanning. IEEE Trans. Antennas Propag. 2016, 64, 1536-1541. [CrossRef]

145. Towfiq, M.A.; Bahceci, I.; Blanch, S.; Romeu, J.; Jofre, L.; Cetiner, B.A. A reconfigurable antenna with beam steering and beamwidth variability for wireless communications. IEEE Trans. Antennas Propag. 2018, 66, 5052-5063. [CrossRef]

146. Mantash, M.; Denidni, T.A. CP Antenna Array With Switching-Beam Capability Using Electromagnetic Periodic Structures for 5G Applications. IEEE Access 2019, 7, 26192-26199. [CrossRef]

147. Wang, S.; Feresidis, A.; Goussetis, G.; Vardaxoglou, J. Low-profile resonant cavity antenna with artificial magnetic conductor ground plane. Electron. Lett. 2004, 40, 405-406. [CrossRef]

148. Feresidis, A.P.; Goussetis, G.; Wang, S.; Vardaxoglou, J.C. Artificial magnetic conductor surfaces and their application to low-profile high-gain planar antennas. IEEE Trans. Antennas Propag. 2005, 53, $209-215$. [CrossRef]

149. Zhou, L.; Li, H.; Qin, Y.; Wei, Z.; Chan, C. Directive emissions from subwavelength metamaterial-based cavities. Appl. Phys. Lett. 2005, 86, 101101. [CrossRef]

150. Ourir, A.; de Lustrac, A.; Lourtioz, J.M. All-metamaterial-based subwavelength cavities $(\lambda / 60)$ for ultrathin directive antennas. Appl. Phys. Lett. 2006, 88, 084103. [CrossRef]

151. Kelly, J.R.; Kokkinos, T.; Feresidis, A.P. Analysis and design of sub-wavelength resonant cavity type 2-D leaky-wave antennas. IEEE Trans. Antennas Propag. 2008, 56, 2817-2825. [CrossRef]

152. Mateo-Segura, C.; Goussetis, G.; Feresidis, A.P. Sub-wavelength profile 2-D leaky-wave antennas with two periodic layers. IEEE Trans. Antennas Propag. 2010, 59, 416-424. [CrossRef]

153. Honari, M.M.; Mousavi, P.; Sarabandi, K. Miniaturized-Element Frequency Selective Surface Metamaterials: A Solution to Enhance Radiation Off of RFICs. IEEE Trans. Antennas Propag. 2019, 68, 1962-1972.

154. Konstantinidis, K.; Feresidis, A.P.; Hall, P.S. Dual subwavelength Fabry-Perot cavities for broadband highly directive antennas. IEEE Antennas Wirel. Propag. Lett. 2014, 13, 1184-1186. [CrossRef]

155. Lin, F.H.; Chen, Z.N. Low-profile wideband metasurface antennas using characteristic mode analysis. IEEE Trans. Antennas Propag. 2017, 65, 1706-1713. [CrossRef] 
156. Qin, F.; Gao, S.; Luo, Q.; Wei, G.; Xu, J.; Li, J.; Wu, C.; Gu, C.; Mao, C. A triband low-profile high-gain planar antenna using Fabry-Perot cavity. IEEE Trans. Antennas Propag. 2017, 65, 2683-2688. [CrossRef]

157. Deng, F.; Qi, J. Shrinking Profile of Fabry-Perot Cavity Antennas with Stratified Metasurfaces: Accurate Equivalent Circuit Design and Broadband High-Gain Performance. IEEE Antennas Wirel. Propag. Lett. 2019, 19, 208-212.

158. Ge, Y.; Esselle, K.P.; Bird, T.S. A method to design dual-band, high-directivity EBG resonator antennas using single-resonant, single-layer partially reflective surfaces. Prog. Electromagnet. Res. 2010, 13, $245-257$. [CrossRef]

159. Moghadas, H.; Daneshmand, M.; Mousavi, P. A dual-band high-gain resonant cavity antenna with orthogonal polarizations. IEEE Antennas Wirel. Propag. Lett. 2011, 10, 1220-1223. [CrossRef]

160. Zeb, B.A.; Ge, Y.; Esselle, K.P.; Sun, Z.; Tobar, M.E. A simple dual-band electromagnetic band gap resonator antenna based on inverted reflection phase gradient. IEEE Trans. Antennas Propag. 2012, 60, 4522-4529. [CrossRef]

161. Moghadas, H.; Daneshmand, M.; Mousavi, P. Single-layer partially reflective surface for an orthogonallypolarised dual-band high-gain resonant cavity antenna. IET Microw. Antennas Propag. 2013, 7, 656-662. [CrossRef]

162. Meng, F.; Sharma, S.K. A dual-band high-gain resonant cavity antenna with a single layer superstrate. IEEE Trans. Antennas Propag. 2015, 63, 2320-2325. [CrossRef]

163. Lv, Y.H.; Ding, X.; Wang, B.Z. Dual-Wideband High-Gain Fabry-Perot Cavity Antenna. IEEE Access 2019, 68, 1389-1401.

(C) 2020 by the authors. Licensee MDPI, Basel, Switzerland. This article is an open access article distributed under the terms and conditions of the Creative Commons Attribution (CC BY) license (http://creativecommons.org/licenses/by/4.0/). 